\title{
Proteomic characterization of paired non- malignant and malignant African-American prostate epithelial cell lines distinguishes them by structural proteins
}

\author{
Jennifer S. Myers ${ }^{1}$, Karin A. Vallega', Jason White², Kaixian Yu ${ }^{3}$, Clayton C. Yates ${ }^{2}$ and Qing-Xiang Amy Sang ${ }^{1 *}$
}

\begin{abstract}
Background: While many factors may contribute to the higher prostate cancer incidence and mortality experienced by African-American men compared to their counterparts, the contribution of tumor biology is underexplored due to inadequate availability of African-American patient-derived cell lines and specimens. Here, we characterize the proteomes of non-malignant RC-77 N/E and malignant RC-77 T/E prostate epithelial cell lines previously established from prostate specimens from the same African-American patient with early stage primary prostate cancer.
\end{abstract}

Methods: In this comparative proteomic analysis of RC-77 N/E and RC-77 T/E cells, differentially expressed proteins were identified and analyzed for overrepresentation of PANTHER protein classes, Gene Ontology annotations, and pathways. The enrichment of gene sets and pathway significance were assessed using Gene Set Enrichment Analysis and Signaling Pathway Impact Analysis, respectively. The gene and protein expression data of age- and stage-matched prostate cancer specimens from The Cancer Genome Atlas were analyzed.

Results: Structural and cytoskeletal proteins were differentially expressed and statistically overrepresented between RC-77 N/E and RC-77 T/E cells. Beta-catenin, alpha-actinin-1, and filamin-A were upregulated in the tumorigenic RC-77 T/E cells, while integrin beta-1, integrin alpha-6, caveolin-1, laminin subunit gamma-2, and CD44 antigen were downregulated. The increased protein level of beta-catenin and the reduction of caveolin-1 protein level in the tumorigenic RC-77 T/E cells mirrored the upregulation of beta-catenin mRNA and downregulation of caveolin-1 mRNA in African-American prostate cancer specimens compared to non-malignant controls. After subtracting race-specific non-malignant RNA expression, beta-catenin and caveolin-1 mRNA expression levels were higher in African-American prostate cancer specimens than in Caucasian-American specimens. The "ECM-Receptor Interaction" and "Cell Adhesion Molecules", and the "Tight Junction" and "Adherens Junction" pathways contained proteins are associated with RC-77 N/E and RC-77 T/E cells, respectively.

Conclusions: Our results suggest RC-77 T/E and RC-77 N/E cell lines can be distinguished by differentially expressed structural and cytoskeletal proteins, which appeared in several pathways across multiple analyses. Our results indicate that the expression of beta-catenin and caveolin-1 may be prostate cancer- and race-specific. Although the RC-77 cell model may not be representative of all African-American prostate cancer due to tumor heterogeneity, it is a unique resource for studying prostate cancer initiation and progression.

Keywords: Prostate cancer, RC-77 T/E, African-American cell line model, Comparative proteomics, Differentially expressed proteins, Cancer health disparity, Beta-catenin, Caveolin-1, Integrins

\footnotetext{
* Correspondence: qxsang@chem.fsu.edu

${ }^{1}$ Department of Chemistry and Biochemistry and Institute of Molecular

Biophysics, Florida State University, 95 Chieftan Way, Tallahassee, FL

32306-4390, USA

Full list of author information is available at the end of the article
}

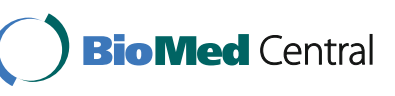

(c) The Author(s). 2017 Open Access This article is distributed under the terms of the Creative Commons Attribution 4.0 International License (http://creativecommons.org/licenses/by/4.0/), which permits unrestricted use, distribution, and reproduction in any medium, provided you give appropriate credit to the original author(s) and the source, provide a link to the Creative Commons license, and indicate if changes were made. The Creative Commons Public Domain Dedication waiver (http://creativecommons.org/publicdomain/zero/1.0/) applies to the data made available in this article, unless otherwise stated. 


\section{Background}

Prostate cancer continues to be a substantial burden in the American population. It remains the second leading cause of cancer death among American men, and model-based estimates continue to predict prostate cancer to be most frequently diagnosed among new cancer cases in American men [1]. Prostate cancer is particularly intriguing because of the striking racial health disparity between African-American and Caucasian-American patients. In the most recent data, African-American men have had the highest prostate cancer incidence and mortality of any race and ethnicity in the United States [1]. Race is a significant risk factor for prostate cancer: African-American men are more likely to receive a prostate cancer diagnosis, with a reported incidence rate between 1.5 and 1.86 times higher in African-American men than in Caucasian-American men [1-3]. AfricanAmerican men are also more likely to receive that diagnosis at a younger age, 3 years younger than Caucasian-American men $[4,5]$. Furthermore, prostate cancer mortality is twice as high in African-American men compared to Caucasian-American men $[1,6]$.

Prostate cancer racial disparities between AfricanAmerican and Caucasian-American patients often reflect more advanced or aggressive cancer in African-American men. African-American men present with higher grade tumors, report more treatment-related side effects, and have shorter progression-free survival [5]. Men with high-risk prostate cancer were more likely to be African-American, even in patients with low prostate-specific antigen levels [7]. Tumor volumes were reported to be larger in African-American men compared to matched CaucasianAmerican specimens [8]. Higher Gleason scores and cancer volumes were also reported in African-American men compared to Caucasian-Americans [9]. Gene and microRNA profiling of African-American and CaucasianAmerican tumor tissue have demonstrated racial variation [10-17]. In light of this, it is increasingly important to study prostate cancer in the context of race, as tumor characteristics have been shown to vary by race. Although socioeconomic factors, treatment choices, comorbidities, and quality of medical care factor into higher incidence and mortality rates, increased prostate cancer-specific mortality is largely attributed to tumor characteristics [18].

One approach to exploring the mechanisms of prostate cancer development and progression is the use of prostate cancer-derived cell lines as in vitro models of the disease. PC-3, DU145, and LNCaP cell lines are popular, well-established, and well-characterized prostate cancer research models [19-21]. The gene and protein expression profiles of these cell lines and their derivatives have also been outlined [19-25]. According to American Type Culture Collection data sheets, PC-3,
DU145, and LNCaP cell lines were established from Caucasian prostate cancer patients aged 59 to 69 years old. The PC-3 cell line was established from a prostatic adenocarcinoma metastatic to bone, and PC-3 cells have features common to neoplastic cells and do not respond to androgen [23]. The DU145 cell line was established from a brain metastasis of human prostate carcinoma, and DU145 cells do not express androgen receptors $[19,21]$. The LNCaP cell line was established from a supraclavicular lymph node metastatic lesion of prostate adenocarcinoma. While LNCaP cells express androgen receptors and grow in response to androgen, they lose this requirement for growth in later passages [23]. Cell lines derived from non-African-American backgrounds may be less beneficial in providing an understanding of the factors leading to high prostate cancer risk in African-American men. They may also be inadequate for explaining the aggressiveness of prostate cancer in African-American men. However, few prostate cancer models have been established from African-American patients. E006AA is an epithelial cell line with low tumorigenicity derived from cancerous tissue of an African-American patient diagnosed with clinically localized T2aN0M0 prostate cancer [26]. Another cell line, E006AA-hT, which was derived from E006AA cells, is highly tumorigenic [27]. The non-neoplastic RC-165 N cell line was derived from benign tissue of an African-American patient and immortalized by telomerase [28]. MDA PCa 2a and MDA PCA 2b cell lines were derived from a bone metastasis of an androgen-independent cancer from an African-American patient [29]. These cell lines are tumorigenic but have deviated from the androgen insensitive phenotype from which they were derived (i.e., the cells behave differently in vivo and in vitro). None of the above-mentioned models is a malignant and non-malignant pair.

The human malignant and non-malignant immortalized prostate epithelial cell lines $\mathrm{RC}-77 \mathrm{~T} / \mathrm{E}$ and $\mathrm{RC}$ $77 \mathrm{~N} / \mathrm{E}$ were established previously from prostate tissue from an African-American patient [30]. This primary tumor was a stage T3c poorly differentiated adenocarcinoma of Gleason score 7. RC-77 cell lines have epithelial character, have functioning androgen receptors, are immortalized, and form a malignant and non-malignant pair. There are few studies on RC-77 cell lines. To date, the $\mathrm{RC}-77$ cell lines have been characterized in terms of miRNA expression, ATP-binding cassette sub-family D member 3 (ABCD3) gene expression, roundabout homo$\log 1$ (ROBO1) mRNA and protein expression, and $B$ lymphoma Mo-MLV insertion region 1 homolog (BMI1) protein levels $[17,31-34]$. This work is the only comprehensive proteomic characterization of RC-77 T/E and RC-77 N/E cell lines. 


\section{Methods}

\section{Cell culture and lysis}

Both RC-77 N/E and RC-77 T/E cell lines were cultured in Keratinocyte-SFM medium supplemented with bovine pituitary extract and recombinant epidermal growth factor (Life Technologies, Inc., Gaithersburg, MD) in a fully humidified incubator containing 95\% air and 5\% $\mathrm{CO}_{2}$ at $37{ }^{\circ} \mathrm{C}$. After aspirating culture medium, cells were washed twice with phosphate-buffered saline. The washed cells were collected and lysed on ice for $10 \mathrm{~min}$ in NP-40 lysis buffer (50 mM Tris- $\mathrm{HCl} \mathrm{pH} \mathrm{7.2;} 150 \mathrm{mM}$ $\mathrm{NaCl} ; 1 \%$ Triton X-100; $0.1 \%$ sodium dodecyl sulfate; $0.2 \%$ sodium deoxycholate in water) containing an EDTA-free protease and phosphatase inhibitor cocktail (Thermo-Pierce, Rockford, IL) at a ratio of $20 \mu \mathrm{L}$ buffer/ 500,000 cells. Cell lysates were spun at $14,000 \mathrm{rpm}$ at $4{ }^{\circ} \mathrm{C}$ for $10 \mathrm{~min}$. The supernatant was collected and the pellet discarded.

\section{Mass spectrometry}

Cell lysates were desalted on Zeba ${ }^{\mathrm{Tm}}$ Desalt Spin Columns (Thermo-Pierce, Rockford, IL). Using a ProteoExtract ${ }^{\mathrm{TM}}$ All-in-One Trypsin Digestion Kit (Calbiochem, Darmstadt, Germany), vacuum-dried cell lysates were re-suspended, and proteins were extracted into a mass spectrometrycompatible buffer then digested with trypsin. Protein expression was analyzed by high-resolution electrospray tandem mass spectrometry (MS/MS) with an externally calibrated Thermo LTQ Orbitrap Velos mass spectrometer. For each of three biological replicates, nanospray liquid chromatography-MS/MS was run in technical triplicate, and all measurements were performed at room temperature. Technical details of the mass spectrometry analyses can be found in the Additional Files (see Additional file 1). The threshold for peptide identification was set at $95 \%$ confidence and the stringency for protein identification was set at $99 \%$ confidence with at least 2 peptide matches.

\section{Data processing and analysis}

Protein expression data was captured in the form of spectral counts, and any non-integer values were rounded up to the nearest whole integer. Each identified protein was mapped to a single gene symbol and Entrez ID. For protein isoforms, expression counts were summed to generate a single dataset for each gene. Such 1:1 mapping was required in downstream analyses. The $\mathrm{R}$ programming environment (version 3.2.1) [35] was used to process the spectral count data as described above, to perform statistical calculations, and to plot data. Differential protein expression between $\mathrm{RC}-77 \mathrm{~T} / \mathrm{E}$ and $\mathrm{RC}-77 \mathrm{~N} / \mathrm{E}$ cell lines was assessed using the processed spectral count data by an unpaired Wilcoxon rank-sum test with an applied continuity correction and two-sided alternative hypothesis via a built-in $\mathrm{R}$ function. Differentially expressed proteins (DEPs) were defined as those proteins whose mean spectral count differed between the two comparison sets with at least $90 \%$ confidence after adjusting for the false discovery rate using the Benjamini-Hochberg function. Next, fold changes in protein expression levels between $\mathrm{RC}$ $77 \mathrm{~T} / \mathrm{E}$ and RC-77 N/E cell lines were calculated by taking the base 2 logarithm $\left(\log _{2}\right)$ of the ratio of the mean spectral count of RC-77 T/E samples to the mean spectral count of RC-77 N/E samples. In this way, proteins downregulated in RC-77 T/E showed negative fold changes, whereas proteins upregulated in RC-77 T/E showed positive fold changes. For samples with zero means, the data was transformed by adding one to both means, which did not substantially affect the results of downstream analysis. A MA plot was constructed to confirm that variance remained stable (see Additional file 2).

\section{Overrepresentation analysis}

To reveal any patterns in the classes or functions of proteins differentially expressed between RC-77 T/E and RC-77 N/E cell lines, DEPs were subjected to overrepresentation analysis using Protein ANalysis THrough Evolutionary Relationships (PANTHER) analysis tools [36]. The list of DEPs was loaded into the PANTHER Classification System data analysis tool (version 11.1), which sorted the DEPs by PANTHER protein class and Gene Ontology (GO) annotations. Using the same list of DEPs, the PANTHER statistical overrepresentation tool (release 20,161,024) was used to assess the probability that the number of DEPs belonging to each protein class or GO category was greater than the number expected in each category picked at random based on a reference human genome. Additionally, the overrepresentation of entire pathways among DEPs was assessed using the National Cancer Institute-Nature Pathway Interaction Database [37]. The list of DEPs was uploaded and searched against this database, and the overrepresentation of pathways was calculated, adjusting probabilities for multiple-hypotheses testing. To determine if the results obtained for DEPs were due to random chance, the same overrepresentation analyses were conducted for 1000 random sets containing the same number of proteins as DEPs sampled from the remaining non-differentially expressed proteins and from the total number of identified proteins detected by mass spectrometry.

\section{Gene set enrichment analysis}

Gene Set Enrichment Analysis (GSEA) (version 2.2.0), which is a type of correlation analysis that uses expression data to associate gene sets with a particular phenotype [38], was used to identify groups of genes associated with either RC-77 T/E or RC-77 N/E cells. So as not to bias against small changes in expression, the processed protein 
spectral count data were inputted into the software without filtering for differential expression, and the $\log _{2}$ fold change was ignored. Proteins that could not be mapped to an Entrez ID were excluded from this analysis. Gene sets containing a minimum of 5 genes and up to a maximum of 500 genes were pulled from BioCarta and Reactome databases (downloaded from the GSEA's Molecular Signatures Database, version 5) and from a customized database of relevant KEGG (Kyoto Encyclopedia of Genes and Genomes) pathways (see Additional file 3). The GSEA software interrogated each gene set against a list of the protein data ranked by correlation to RC$77 \mathrm{~T} / \mathrm{E}$ or RC-77 N/E samples to determine which proteins from the ranked list appeared in a given pathway and whether they were randomly distributed or clustered among a phenotype. Enrichment (relative to RC-77 N/E) was based on the number of highly correlated genes from the ranked list that appeared in the pathway with a chosen FDR cut-off of $\mathrm{q}<0.25$.

\section{Signaling pathway impact analysis}

Signaling Pathway Impact Analysis (SPIA) was used to provide a system-level assessment of pathway significance by incorporating overrepresentation, a function of differential expression and the magnitude of expression change (as a $\log _{2}$ ratio), and topology, the position of the protein in a pathway [39]. Pathway topology is important because it distinguishes genes or proteins that may be at trigger, regulatory, divergent, or end positions. SPIA was completed using the "SPIA" $\mathrm{R}$ package (version 2.18.0). The processed protein spectral count data including the results of the differential expression analysis and $\log _{2}$ fold changes were uploaded. Proteins that could not be mapped to an Entrez ID were excluded from this analysis. The threshold for differential expression was set to $\mathrm{q}<0.1$. The same relevant KEGG pathways used in GSEA were used for SPIA (see Additional file 3). KEGG pathways were chosen because they contain information about pathway topology. SPIA calculated the overrepresentation and perturbation probabilities and combined them into a global probability that a pathway was activated or inhibited in RC-77 T/E cells. The overrepresentation probability reflects the likelihood the number of DEPs observed in a pathway was larger than that observed by random chance. The perturbation probability reflects whether the positions of DEPs in a particular pathway were at crucial junctions that could perturb the pathway. The false discovery rate-adjusted global probability was the metric used to rank the significance of the pathways.

\section{Analysis of DEPs relevance in human prostate cancer patient specimens}

Using The Cancer Genome Atlas (TCGA) prostate adenocarcinoma (PRAD) cohort, a dataset of 12 age- and stage-matched African-American and CaucasianAmerican specimen pairs (24 specimens total) was created. These specimen pairs were used to investigate how the protein and RNA expression of the 63 DEPs differed by race. To generate the dataset, TCGA protein data was downloaded from CBioportal, and TCGA RNA expression data was downloaded from FireBrowse.org. Both are repositories for TCGA data. The protein data available from the TCGA PRAD cohort was obtained via Reverse Phase Protein Array and was limited to 219 proteins. TCGA RNA expression data was obtained through Illumina HiSeq (RNA sequencing) and comprised over 20,000 gene transcripts. Only DEPs present in both datasets were carried forward for further analysis. Because the RC-77 T/E cell line was generated from an early stage primary tumor, only tumors with a Gleason score of 6 or 7 were included (see Additional file 4). Data frames of extracted protein and RNA expression data were created with Microsoft Excel.

Because protein data for non-malignant PRAD specimens was not available in TCGA data and non-malignant PRAD tissue was not collected from all patients, direct tumor-to-non-malignant comparisons could not be performed. In order to compare expression distributions, the average of the race-specific non-malignant PRAD RNA expression was subtracted from the age- and stagematched tumor specimens (see Additional file 4). Of the 499 individuals in TCGA PRAD patient cohort, 51 had non-malignant PRAD tissue RNA expression data. After filtering for Gleason score $(\leq 7)$ ), 34 (4 African-American and 30 Caucasian-American) non-malignant prostate tissue specimens were included in the non-malignantexpression-normalized analysis (see Additional file 4). The statistical significance of differences between African-American and Caucasian-American patient specimens were analyzed using the "t.test" function in R.

\section{Results}

Overall, 843 proteins were identified by mass spectrometry, and 833 proteins remained in the dataset after processing to consolidate isoforms (see Additional files 5 and 6, respectively). These 833 proteins formed the dataset used in GSEA and SPIA analysis. Between RC-77 T/ $\mathrm{E}$ and RC-77 N/E cell lines, 744 proteins were shared, 74 proteins were detected in RC-77 T/E cells but not RC$77 \mathrm{~N} / \mathrm{E}$ cells, and 15 proteins were detected in RC-77 N/ $\mathrm{E}$ but not RC-77 T/E cells. In total, expression levels of 200 proteins varied between RC-77 T/E and RC-77 N/E cells $(p<0.05$, Wilcoxon rank-sum test); but after correcting for the false-discovery rate, only 63 proteins retained significance $(\mathrm{q}<0.1)$. These 63 proteins formed the list of DEPs: 17 proteins downregulated in RC-77 T/ $\mathrm{E}$ cells and 46 proteins upregulated in RC-77 T/E cells (Table 1). A full listing of protein expression changes 
Table 1 Differentially expressed proteins between RC-77 T/E and RC-77 N/E cell lines

\begin{tabular}{|c|c|c|c|c|c|}
\hline Identified Proteins (Gene Symbol) & $p$-value & $q$-value & $\begin{array}{l}\text { Log }_{2} \text { Fold } \\
\text { Change }\end{array}$ & Status in RC-77 T/E Cells & $\begin{array}{l}\text { Significant Pathway or Gene Set } \\
\text { Involvement }\end{array}$ \\
\hline CD166 antigen (ALCAM) & $5.90 \mathrm{E}-04$ & 4.91E-02 & -2.12 & Downregulated & \\
\hline${ }^{*}$ Caveolin-1 (CAV1) & $2.98 \mathrm{E}-04$ & 4.91E-02 & -1.72 & Downregulated & Focal Adhesion; Proteoglycans in Cancer \\
\hline *Vimentin (VIM) & 4.09E-04 & 4.91E-02 & -1.61 & Downregulated & \\
\hline *Myosin heavy chain-9 (MYH9) & 4.04E-04 & 4.91E-02 & 1.58 & Upregulated & \\
\hline $\begin{array}{l}\text { SH3 domain-binding glutamic } \\
\text { acid-rich-like protein } 3 \text { (SH3BGRL3) }\end{array}$ & $2.68 \mathrm{E}-04$ & 4.91E-02 & 2.70 & Upregulated & \\
\hline $\begin{array}{l}\text { Eukaryotic translation initiation } \\
\text { factor } 4 B \text { (EIF4B) }\end{array}$ & $5.78 \mathrm{E}-04$ & 4.91E-02 & 2.77 & Upregulated & \\
\hline Calpastatin (CAST) & $3.55 \mathrm{E}-04$ & 4.91E-02 & 3.09 & Upregulated & \\
\hline Nucleolar RNA helicase 2 (DDX21) & 4.16E-04 & 4.91E-02 & 3.20 & Upregulated & \\
\hline Creatine kinase U-type (CKMT1A) & 3.36E-04 & 4.91E-02 & 3.46 & Upregulated & \\
\hline $\begin{array}{l}\text { Thioredoxin domain-containing } \\
\text { protein } 17 \text { (TXNDC17) }\end{array}$ & 4.92E-04 & 4.91E-02 & 1.69 & RC-77 T/E only & \\
\hline *Type I cytoskeletal keratin 19 (KRT19) & 7.77E-04 & $5.40 \mathrm{E}-02$ & -2.49 & Downregulated & \\
\hline Serotransferrin (TF) & $7.29 \mathrm{E}-04$ & $5.40 \mathrm{E}-02$ & -2.30 & Downregulated & \\
\hline Integrin alpha-6 (ITGA6) & $1.44 \mathrm{E}-03$ & $5.40 \mathrm{E}-02$ & -1.93 & Downregulated & $\begin{array}{l}\text { Cell Adhesion Molecules; ECM-Receptor } \\
\text { Interaction; Small Cell Lung Cancer }\end{array}$ \\
\hline Laminin subunit gamma-2 (LAMC2) & $9.86 \mathrm{E}-04$ & $5.40 \mathrm{E}-02$ & -1.72 & Downregulated & $\begin{array}{l}\text { ECM-Receptor Interaction; Small Cell } \\
\text { Lung Cancer; Focal Adhesion }\end{array}$ \\
\hline CD59 glycoprotein (CD59) & $9.15 \mathrm{E}-04$ & $5.40 \mathrm{E}-02$ & -1.65 & Downregulated & \\
\hline Squalene synthase (FDFT1) & $1.23 \mathrm{E}-03$ & $5.40 \mathrm{E}-02$ & -1.31 & Downregulated & \\
\hline${ }^{*}$ Filamin-A (FLNA) & $1.06 \mathrm{E}-03$ & $5.40 \mathrm{E}-02$ & 1.21 & Upregulated & Focal Adhesion, Proteoglycans in Cancer \\
\hline $\begin{array}{l}\text { Hydroxyacyl-coenzyme A dehydrogenase } \\
\text { (HADH) }\end{array}$ & $1.61 \mathrm{E}-03$ & $5.40 \mathrm{E}-02$ & 1.22 & Upregulated & \\
\hline $\begin{array}{l}\text { X-ray repair cross-complementing protein } \\
5 \text { (XRCC5) }\end{array}$ & $1.42 \mathrm{E}-03$ & $5.40 \mathrm{E}-02$ & 1.35 & Upregulated & \\
\hline Prothymosin alpha (PTMA) & $1.49 \mathrm{E}-03$ & 5.40E-02 & 1.65 & Upregulated & \\
\hline $\begin{array}{l}\text { Cytosolic acyl coenzyme A thioester } \\
\text { hydrolase (ACOT7) }\end{array}$ & 1.37E-03 & 5.40E-02 & 1.74 & Upregulated & \\
\hline $\begin{array}{l}\text { High mobility group protein HMG-1/HMG-Y } \\
\text { (HMGA1) }\end{array}$ & $1.58 \mathrm{E}-03$ & $5.40 \mathrm{E}-02$ & 1.79 & Upregulated & \\
\hline $\begin{array}{l}\text { Putative pre-mRNA-splicing factor ATP- } \\
\text { dependent RNA helicase DHX15 (DHX15) }\end{array}$ & $1.10 \mathrm{E}-03$ & $5.40 \mathrm{E}-02$ & 2.10 & Upregulated & \\
\hline Scaffold attachment factor B1 (SAFB) & $1.59 \mathrm{E}-03$ & $5.40 \mathrm{E}-02$ & 2.27 & Upregulated & \\
\hline Nucleoprotein TPR (TPR) & $1.62 \mathrm{E}-03$ & $5.40 \mathrm{E}-02$ & 3.52 & Upregulated & \\
\hline Hemoglobin subunit alpha (HBA1) & $1.80 \mathrm{E}-03$ & $5.54 \mathrm{E}-02$ & -1.87 & RC-77 N/E only & \\
\hline Protein PML (PML) & 1.77E-03 & 5.54E-02 & 1.69 & RC-77 T/E only & \\
\hline Ribosome-binding protein 1 (RRBP1) & $1.89 \mathrm{E}-03$ & $5.63 \mathrm{E}-02$ & 1.64 & Upregulated & \\
\hline Adenosylhomocysteinase (AHCY) & $2.00 \mathrm{E}-03$ & $5.75 \mathrm{E}-02$ & 1.68 & Upregulated & \\
\hline Gamma-interferon-inducible protein 16 (IFI16) & 2.37E-03 & $6.59 \mathrm{E}-02$ & 1.39 & Upregulated & \\
\hline Phosphoenolpyruvate carboxykinase (PCK2) & $2.51 \mathrm{E}-03$ & $6.75 \mathrm{E}-02$ & 3.04 & Upregulated & \\
\hline 14-3-3 protein sigma (SFN) & $2.60 \mathrm{E}-03$ & $6.76 \mathrm{E}-02$ & 1.49 & Upregulated & \\
\hline *Lamin-B1 (LMNB1) & 3.04E-03 & $7.26 \mathrm{E}-02$ & -0.87 & Downregulated & \\
\hline *Alpha-actinin-1 (ACTN1) & $3.05 \mathrm{E}-03$ & 7.26E-02 & 1.06 & Upregulated & $\begin{array}{l}\text { Tight Junction; Adherens Junction; } \\
\text { Hippo Signaling Pathway; Focal Adhesion }\end{array}$ \\
\hline High mobility group protein HMGI-C (HMGA2) & $2.95 \mathrm{E}-03$ & 7.26E-02 & 2.19 & Upregulated & \\
\hline
\end{tabular}


Table 1 Differentially expressed proteins between RC-77 T/E and RC-77 N/E cell lines (Continued)

\begin{tabular}{|c|c|c|c|c|c|}
\hline $\begin{array}{l}\text { Voltage-dependent anion-selective } \\
\text { channel protein } 1 \text { (VDAC1) }\end{array}$ & 4.59E-03 & 7.67E-02 & -1.00 & Downregulated & \\
\hline Integrin beta-1 (ITGB1) & $3.48 \mathrm{E}-03$ & 7.67E-02 & -0.92 & Downregulated & $\begin{array}{l}\text { Cell Adhesion Molecules; ECM-Receptor } \\
\text { Interaction; Small Cell Lung Cancer }\end{array}$ \\
\hline $\begin{array}{l}\text { Non-histone chromosomal protein } \\
\text { HMG-17 (HMGN2) }\end{array}$ & $4.22 \mathrm{E}-03$ & 7.67E-02 & 1.34 & Upregulated & \\
\hline *PDZ and LIM domain protein 1 (PDLIM1) & 4.40E-03 & 7.67E-02 & 1.61 & Upregulated & \\
\hline T-complex protein 1 subunit epsilon (CCT5) & $4.72 \mathrm{E}-03$ & 7.67E-02 & 1.66 & Upregulated & \\
\hline Aminopeptidase N (ANPEP) & $5.25 \mathrm{E}-03$ & 7.67E-02 & -2.38 & RC-77 N/E only & \\
\hline Prefoldin subunit 2 (PFDN2) & 4.96E-03 & 7.67E-02 & 1.35 & RC-77 T/E only & \\
\hline 40 S ribosomal protein S24 (RPS24) & 4.96E-03 & 7.67E-02 & 1.35 & RC-77 T/E only & \\
\hline Serine/arginine-rich splicing factor 1 (SRSF1) & 4.96E-03 & 7.67E-02 & 1.35 & RC-77 T/E only & \\
\hline S-formylglutathione hydrolase (ESD) & 5.05E-03 & 7.67E-02 & 1.42 & RC-77 T/E only & \\
\hline RNA-binding protein EWS (EWSR1) & 5.15E-03 & 7.67E-02 & 1.47 & RC-77 T/E only & \\
\hline Hepatoma-derived growth factor (HDGF) & 5.15E-03 & 7.67E-02 & 1.47 & RC-77 T/E only & \\
\hline $\begin{array}{l}\text { Non-histone chromosomal protein } \\
\text { HMG-14 (HMGN1) }\end{array}$ & 4.96E-03 & 7.67E-02 & 1.47 & RC-77 T/E only & \\
\hline $\begin{array}{l}\text { S-methyl-5'-thioadenosine } \\
\text { phosphorylase (MTAP) }\end{array}$ & 4.96E-03 & 7.67E-02 & 1.47 & RC-77 T/E only & \\
\hline Phosphoserine aminotransferase (PSAT1) & 5.15E-03 & 7.67E-02 & 1.53 & RC-77 T/E only & \\
\hline 60 sibosomal protein L10 (RPL10) & 4.99E-03 & 7.67E-02 & 1.53 & RC-77 T/E only & \\
\hline $\begin{array}{l}\text { Proteasome activator complex subunit } \\
3 \text { (PSME3) }\end{array}$ & $5.22 \mathrm{E}-03$ & 7.67E-02 & 1.58 & RC-77 T/E only & \\
\hline 40 S ribosomal protein S11 (RPS11) & 4.99E-03 & 7.67E-02 & 1.64 & RC-77 T/E only & \\
\hline tRNA-splicing ligase RtcB homolog (RTCB) & $5.25 \mathrm{E}-03$ & 7.67E-02 & 1.64 & RC-77 T/E only & \\
\hline $\begin{array}{l}\text { Double-stranded RNA-specific adenosine } \\
\text { deaminase (ADAR) }\end{array}$ & 5.25E-03 & 7.67E-02 & 1.92 & RC-77 T/E only & \\
\hline $\begin{array}{l}\text { Eukaryotic translation initiation factor } 3 \\
\text { subunit I (EIF3I) }\end{array}$ & $5.22 \mathrm{E}-03$ & 7.67E-02 & 1.96 & RC-77 T/E only & \\
\hline 60 S ribosomal protein L35 (RPL35) & $5.18 \mathrm{E}-03$ & 7.67E-02 & 2.08 & RC-77 T/E only & \\
\hline Cytochrome c oxidase subunit 5A (COX5A) & $5.74 \mathrm{E}-03$ & $8.24 \mathrm{E}-02$ & -1.38 & Downregulated & \\
\hline *Beta-catenin (CTNNB1) & $5.93 \mathrm{E}-03$ & 8.37E-02 & 1.40 & Upregulated & $\begin{array}{l}\text { Tight Junction; Adherens Junction; } \\
\text { Hippo Signaling Pathway; } \\
\text { Focal Adhesion }\end{array}$ \\
\hline *Type II cytoskeletal keratin 8 (KRT8) & $6.14 \mathrm{E}-03$ & $8.52 \mathrm{E}-02$ & -1.79 & Downregulated & \\
\hline CD44 antigen (CD44) & $6.44 \mathrm{E}-03$ & 8.60E-02 & -0.77 & Downregulated & $\begin{array}{l}\text { Proteoglycans in Cancer; ECM-Receptor } \\
\text { Interaction }\end{array}$ \\
\hline $\begin{array}{l}\text { Plasminogen activator inhibitor } 1 \\
\text { RNA-binding protein (SERBP1) }\end{array}$ & $6.51 \mathrm{E}-03$ & 8.60E-02 & 1.58 & Upregulated & \\
\hline 605 ribosomal protein L6 (RPL6) & $6.38 \mathrm{E}-03$ & 8.60E-02 & 2.14 & Upregulated & \\
\hline
\end{tabular}

*Carries a "Structural" or "Cytoskeletal" annotation in PANTHER. P-value is the probability the protein differs between RC-77 N/E and RC-77 T/E as calculated by an unpaired Wilcoxon rank-sum test, and q-value is the probability adjusted for multiple hypotheses testing using the Benjamini-Hochberg method. The log ${ }_{2}$ fold change was calculated using the RC-77 T/E to RC-77 N/E ratio. Significant pathway or gene set involvement reflects the results of Gene Set Enrichment Analysis and Signaling Pathway Impact Analysis

between RC-77 N/E and RC-77 T/E cells is found in the Additional files (see Additional file 6). The distribution of $\log _{2}$ fold changes for all proteins was plotted in a 1-D scatter plot (Fig. 1). DEPs tended to have greater than two-fold changes in expression levels, and most $\log _{2}$ fold changes clustered around -2.0 and +1.5 . The reproducibility among biological replicates was good (see Additional files 7 and 8).

\section{Overrepresentation analysis}

For each of the 63 DEPs, PANTHER protein class and GO annotations were pulled from the PANTHER database, 


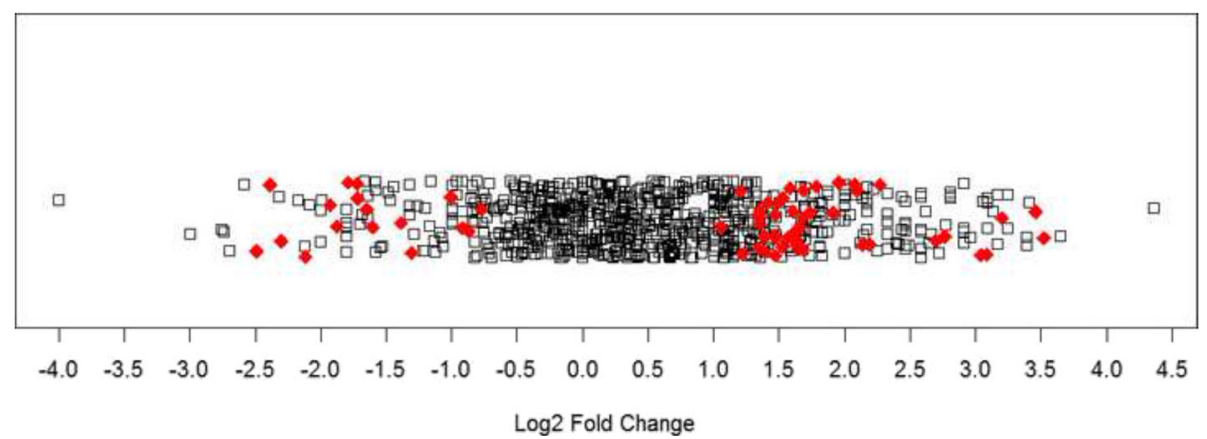

Fig. 1 Magnitude of protein expression changes between RC-77 T/E and RC-77 N/E cell lines. In this one-dimensional scatter plot, the magnitude of protein expression changes is represented by $\log _{2}$ fold ratio. Red diamonds represent differentially expressed proteins. Black squares represent other identified proteins that were not significantly different

and the number of annotations in each category were counted (Fig. 2). No annotations were found for 12 DEPs; however, a pattern of nucleic acid binding and structural proteins emerged among the annotations for the 51 remaining DEPs. "Nucleic Acid Binding" was the most populated PANTHER protein class category with 15 DEPs, while 10 DEPs were classified as "Structural" and/or "Cytoskeletal Proteins", and another 6 DEPs were classified as hydrolases (Table 2). The remaining DEPs were spread nearly evenly across 20 other categories (Fig. 2a). When DEPs were sorted by GO Molecular Function notation (Fig. 2c), the "Binding" and "Catalytic Activity" GO Molecular Function labels each covered over 40\% (21 of 51 DEPs) of the annotated DEPs, and the "Structural Molecule Activity" label was also highly populated (13 of 51 DEPs) (Table 3). Overrepresentation analysis supported the pattern of structural/cytoskeletal proteins among proteins differentially expressed between RC-77 T/E and RC77 N/E cells (Table 4). Only the "Cytoskeletal Protein" PANTHER protein class category $(\mathrm{q}=0.033)$ was statistically overrepresented among the DEPs compared to the reference human genome/proteome (20,814 genes/proteins).

Because structural and cytoskeletal proteins are highly abundant, we verified the results of the enrichment and overrepresentation of this protein class by comparing the results to those obtained using an equivalent number of randomly sampled proteins. We repeated the overrepresentation analysis on 1000 subsets of 63 proteins (the number of DEPs identified) randomly sampled from the 770 non-differentially expressed proteins and from all 833 proteins identified by mass spectrometry compared to the reference human genome/proteome. Among the repeated sets of proteins pulled from the 770 non-DEPs, structural/cytoskeletal proteins protein were significantly overrepresented in only 2 sets; there were no sets from the proteins sampled from all 833 proteins with significant overrepresentation of the structural/cytoskeletal protein class (Table 4). Therefore, we conclude with high probability $(99.8 \%)$ that the overrepresentation of the structural/cytoskeletal protein class among the 63 DEPs is not by random chance. In contrast, many DEPs were labeled with the "Catalytic Activity" GO Molecular Function; however, enzyme protein classes were not overrepresented according to the enrichment test and were more frequent among the random samples. These results verified that the differences between RC-77 T/E and RC-77 N/E cell lines are specifically linked to structural/cytoskeletal proteins because none of the 1000 random subsets of proteins from 770 non-DEPs were enriched in structural proteins relative to the genome/ proteome.

There was a deviation from the pattern of structural/ cytoskeletal protein overrepresentation when DEPs were analyzed by GO Biological Process annotations. Metabolic and cellular processes were the most common GO Biological Process annotation, with 37 and 23 proteins, respectively (Fig. 2B and Table 5). The GO Biological Process category "Metabolic Process" encompasses carbohydrate, lipid, protein, amino acid, and nucloeobasecontaining compound metabolism; and the GO Biological Process term "Cellular Process" is an umbrella heading for cell communication, cell cycle, cytokinesis, and cellular component movement. The GO Biological Process categories "Biological Regulation", "Developmental Process", and "Cellular Component Organization or Biogenesis" were evenly populated (Fig. 2b).

In addition to grouping by PANTHER protein class or GO annotations, pathway overrepresentation among the DEPs was also assessed using the National Cancer Institute-Nature Pathway Interaction Database. Again, structural molecules featured prominently in these pathways, including integrin alpha- 6 , integrin beta- 1 , and beta-catenin (Table 6).

\section{Gene set enrichment analysis}

Although overrepresentation analysis showed that structural proteins and pathways related to structural proteins differed between RC-77 T/E and RC-77 N/E cells, this 


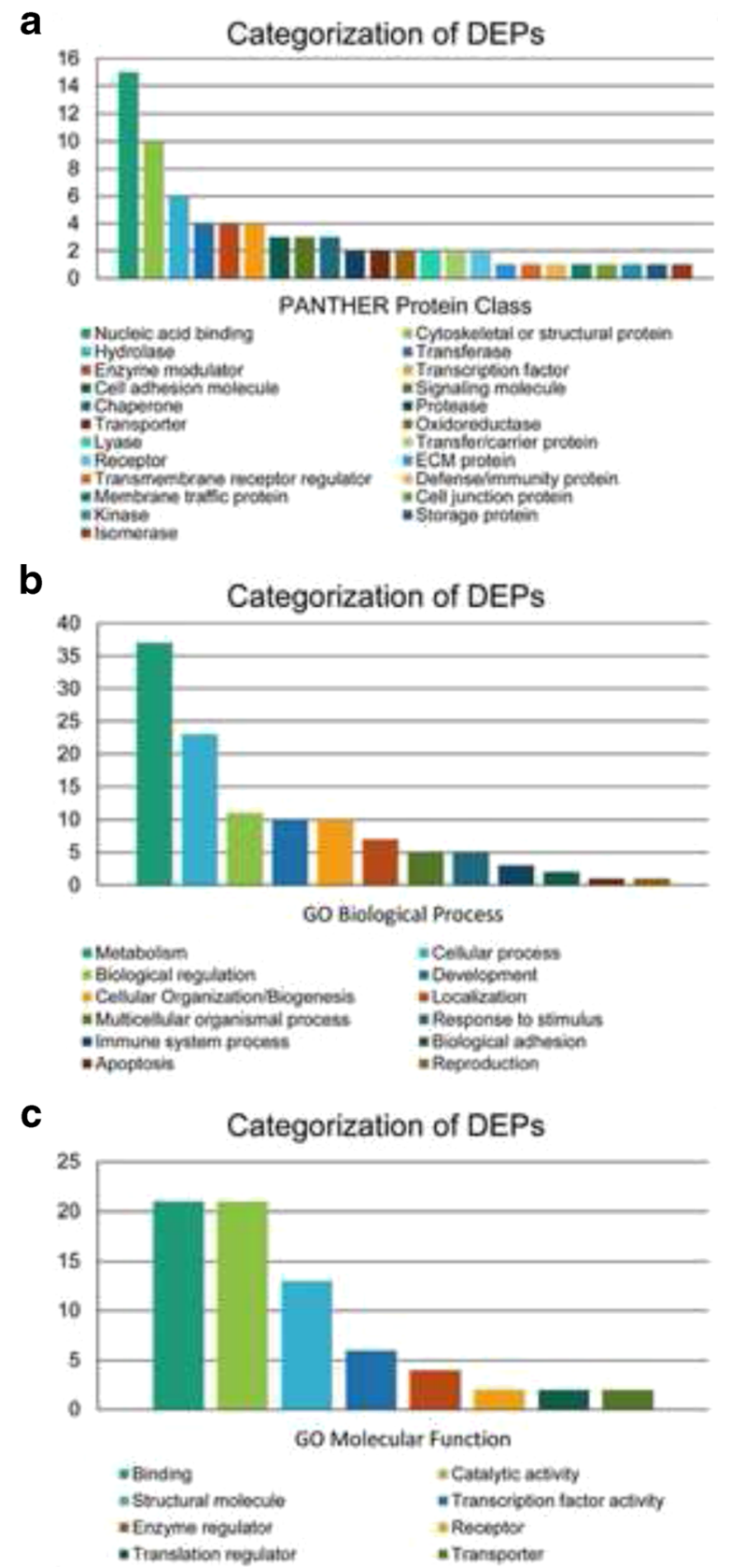

Fig. 2 Functional classification of differentially expressed proteins between RC-77 T/E and RC-77 N/E cell lines. DEPs in RC-77 T/E and RC-77 N/E cell lines were classified according to (A) PANTHER protein class, (B) Biological Process Gene Ontology terms, and (C) Molecular Function Gene Ontology terms. Note: No annotations were found for 12 DEPs (laminin subunit gamma-2, SH3 domain-binding glutamic acid-rich-like protein 3, serine/arginine-rich splicing factor 1, CD44 antigen, tRNA-splicing ligase RtcB homolog, ribosome-binding protein 1, scaffold attachment factor B1, nucleoprotein TPR, integrin alpha-6, protein PML, squalene synthase, and $X$-ray repair cross-complementing protein 5). DEP = differentially expressed protein; PANTHER = PANTHER: Protein ANalysis THrough Evolutionary Relationships analysis did not link these differences directly to either of the cell lines. GSEA identified groups of genes specifically associated with either RC-77 T/E or RC-77 N/E cells. For this analysis, all protein data were used as the input, not just data for the 63 DEPs. Multiple gene sets were enriched in RC-77 T/E and RC-77 N/E cells (Table 7). A complete listing of GSEA results is presented in the Additional files (see Additional file 9). An enriched gene set contained a significant number of proteins whose expression most correlated with either RC-77 T/E or RC-77 N/E cells. The most significantly enriched gene set in RC-77 T/E cells was the KEGG "Tight Junction" gene set. Additionally, the KEGG "Adherens Junction" gene set was highly enriched in RC-77 T/E cells. The most significant gene set enriched in RC-77 N/E cells was the KEGG "Cell Adhesion Molecules", and the KEGG "ECM-Receptor Interaction" gene set was also highly enriched in RC-77 N/E cells. Interestingly, structural proteins contributed to the enrichment of each of these gene sets in their respective cell lines. While alpha-actinin-1 and beta-catenin were associated with RC-77 T/E cells, integrin alpha-6, integrin beta-1, laminin subunit gamma-2, and CD166 antigen were associated with RC-77 N/E cells. These results corroborate the overrepresentation of structural proteins in these cell lines. Furthermore, this enrichment analysis differentiates which structural protein was associated with each cell line.

\section{Signaling pathway impact analysis}

SPIA was conducted to address both the overrepresentation and pathway topology of DEPs to determine whether the DEPs found in a pathway have a meaningful impact within that pathway. SPIA differs from GSEA in two key ways. First, it considers the magnitude of expression and establishes a difference in impact between small and large fold changes. Second, by including a measure of perturbation, SPIA more fully captures the interactions of proteins, which can be lost in overrepresentation analyses and correlation analyses like GSEA. Four KEGG pathways were significantly impacted in the RC-77 T/E cell line: "Focal Adhesion" (false discovery rate-adjusted global probability [pGFdr] $=0.00934$ ), "Small Cell Lung Cancer" (pGFdr = 0.0246), "Proteoglycans in Cancer" (pGFdr = 0.0246), and "ECM-Receptor Interaction" (pGFdr $=0.0246)$ (Table 8). Based on the expression pattern of the DEPs found in the pathway, SPIA predicted these four pathways were inhibited in RC-77 T/E cells. In corroboration, "ECM-Receptor Interaction" and "Small Cell Lung Cancer" were enriched in RC-77 N/E cells according to GSEA results. Pathway images with DEPs highlighted can be found in the full SPIA results presented in the Additional files (see Additional file 10). Note that not all components of 
Table 2 Categorization of differentially expressed proteins according to PANTHER protein class

\begin{tabular}{|c|c|c|}
\hline \multicolumn{3}{|c|}{ PANTHER Protein Class (Number of Differentially Expressed Proteins) } \\
\hline \multicolumn{3}{|c|}{ Nucleic Acid Binding Proteins (15) } \\
\hline - eukaryotic translation initiation factor $4 \mathrm{~B}$ & - RNA-binding protein EWS & • high mobility group protein HMG-1/HMG-Y \\
\hline - high mobility group protein $\mathrm{HMGI}-\mathrm{C}$ & • non-histone chromosomal protein HMG-14 & • non-histone chromosomal protein HMG-17 \\
\hline - 40 S ribosomal protein S24 & - nucleolar RNA helicase 2 & • 605 ribosomal protein L35 \\
\hline • 605 ribosomal protein L6 & - 40 S ribosomal protein S11 & - 605 ribosomal protein L10 \\
\hline $\begin{array}{l}\text { - plasminogen activator inhibitor } 1 \\
\text { RNA-binding protein }\end{array}$ & $\begin{array}{l}\text { - putative pre-mRNA-splicing factor } \\
\text { ATP-dependent RNA helicase DHX15 }\end{array}$ & - double-stranded RNA-specific adenosine deaminase \\
\hline \multicolumn{3}{|l|}{ Structural and/or Cytoskeletal Proteins (10) } \\
\hline - beta-catenin & - filamin-A & - vimentin \\
\hline - lamin-B1 & - alpha-actinin-1 & • caveolin-1 \\
\hline • PDZ and LIM domain protein 1 & - type I cytoskeletal keratin 19 & • type II cytoskeletal keratin 8 \\
\hline \multicolumn{3}{|l|}{ - myosin heavy chain-9 } \\
\hline \multicolumn{3}{|l|}{ Hydrolases (6) } \\
\hline - serotransferrin & - aminopeptidase N & • adenosylhomocysteinase \\
\hline $\begin{array}{l}\text { - double-stranded RNA-specific adenosine } \\
\text { deaminase }\end{array}$ & - cytosolic acyl coenzyme A thioester hydrolase & - S-formylglutathione hydrolase \\
\hline
\end{tabular}

Table 3 Categorization of differentially expressed proteins according to Gene Ontology Molecular Function

\begin{tabular}{|c|c|c|}
\hline \multicolumn{3}{|c|}{ Gene Ontology Molecular Function Annotation (Number of Differentially Expressed Proteins) } \\
\hline \multicolumn{3}{|c|}{ Binding Proteins (21) } \\
\hline - eukaryotic translation initiation factor 4B & - RNA-binding protein EWS & - high mobility group protein HMG-1/HMG-Y \\
\hline $\begin{array}{l}\text { - double-stranded RNA-specific adenosine } \\
\text { deaminase }\end{array}$ & • plasminogen activator inhibitor 1 RNA-binding protein & - non-histone chromosomal protein HMG-17 \\
\hline • alpha-actinin-1 & - nucleolar RNA helicase 2 & • 605 ribosomal protein L35 \\
\hline - hepatoma-derived growth factor & - gamma-interferon-inducible protein 16 & - 605 ribosomal protein L10 \\
\hline - PDZ and LIM domain protein 1 & • non-histone chromosomal protein HMG-14 & - high mobility group protein $\mathrm{HMGI}-\mathrm{C}$ \\
\hline • caveolin-1 & - calpastatin & - beta-catenin \\
\hline - 605 ribosomal protein L6 & - filamin-A & - myosin heavy chain-9 \\
\hline \multicolumn{3}{|l|}{ Catalytic Activity Proteins (21) } \\
\hline - serotransferrin & • aminopeptidase N & - calpastatin \\
\hline $\begin{array}{l}\text { - double-stranded RNA-specific adenosine } \\
\text { deaminase }\end{array}$ & $\begin{array}{l}\text { - putative pre-mRNA-splicing factor ATP-dependent RNA } \\
\text { helicase DHX15 }\end{array}$ & $\begin{array}{l}\text { - type I cytoskeletal high mobility group protein } \\
\text { HMG-I/HMG-Y }\end{array}$ \\
\hline $\begin{array}{l}\text { - cytosolic acyl coenzyme A thioester } \\
\text { hydrolase }\end{array}$ & - hydroxyacyl-coenzyme A dehydrogenase & - S-formylglutathione hydrolase \\
\hline - phosphoenolpyruvate carboxykinase & - cytochrome c oxidase subunit 5A & - S-methyl-5'-thioadenosine phosphorylase \\
\hline - creatine kinase U-type & • 605 ribosomal protein L35 & • caveolin-1 \\
\hline - myosin heavy chain-9 & • adenosylhomocysteinase & - nucleolar RNA helicase 2 \\
\hline - high mobility group protein $\mathrm{HMGI}-\mathrm{C}$ & - phosphoserine aminotransferase & - RNA-binding protein EWS \\
\hline \multicolumn{3}{|l|}{ Structural Molecule Activity (13) } \\
\hline - filamin-A & - 605 ribosomal protein L10 & • 605 ribosomal protein L35 \\
\hline • Type I cytoskeletal keratin 19 & - type II cytoskeletal keratin 8 & - PDZ and LIM domain protein 1 \\
\hline - Myosin heavy chain-9 & - 605 ribosomal protein L6 & - 40S ribosomal protein S11 \\
\hline • alpha-actinin-1 & - vimentin & • lamin-B1 \\
\hline - caveolin-1 & & \\
\hline
\end{tabular}


Table 4 Overrepresentation analysis by PANTHER protein class of differentially expressed proteins and random sets of proteins

\begin{tabular}{|c|c|c|c|c|c|}
\hline \multirow[t]{2}{*}{ Protein Class } & \multirow{2}{*}{$\begin{array}{l}\text { Size of } \\
\text { Class }\end{array}$} & \multicolumn{2}{|c|}{ Overrepresentation Analysis } & \multicolumn{2}{|c|}{ \# Sets per 1000 in Which Significantly Overrepresented } \\
\hline & & $p$-value & $q$-value & Using non-DEPs & Using all Proteins \\
\hline cytoskeletal protein & 198 & 0.001 & 0.033 & 2 & 0 \\
\hline storage protein & 25 & 0.011 & 0.123 & 0 & 7 \\
\hline chaperone & 183 & 0.027 & 0.209 & 100 & 107 \\
\hline transmembrane receptor regulatory & 65 & 0.062 & 0.312 & 0 & 1 \\
\hline lyase & 151 & 0.068 & 0.312 & 28 & 33 \\
\hline nucleic acid binding & 2332 & 0.182 & 0.697 & 1 & 7 \\
\hline cell junction protein & 140 & 0.216 & 0.71 & 0 & 0 \\
\hline isomerase & 162 & 0.266 & 0.766 & 21 & 16 \\
\hline cell adhesion molecule & 458 & 0.317 & 0.81 & 0 & 0 \\
\hline extracellular matrix protein & 363 & 0.393 & 0.825 & 0 & 0 \\
\hline transfer/carrier protein & 364 & 0.395 & 0.825 & 3 & 3 \\
\hline protease & 586 & 0.497 & 0.953 & 0 & 0 \\
\hline membrane traffic protein & 372 & 0.677 & 0.992 & 1 & 1 \\
\hline oxidoreductase & 593 & 0.72 & 0.992 & 94 & 61 \\
\hline kinase & 699 & 0.818 & 0.992 & 0 & 0 \\
\hline hydrolase & 1482 & 0.832 & 0.992 & 0 & 0 \\
\hline defense/immunity protein & 561 & 0.87 & 0.992 & 0 & 0 \\
\hline transferase & 1198 & 0.879 & 0.992 & 0 & 0 \\
\hline signaling molecule & 1083 & 0.915 & 0.992 & 0 & 0 \\
\hline transporter & 920 & 0.933 & 0.992 & 0 & 0 \\
\hline enzyme modulator & 1353 & 0.935 & 0.992 & 0 & 0 \\
\hline transcription factor & 1451 & 0.957 & 0.992 & 0 & 0 \\
\hline receptor & 1813 & 0.992 & 0.992 & 0 & 0 \\
\hline
\end{tabular}

The PANTHER overrepresentation analysis was run on the subset of 63 DEPs and on 1000 subsets of 63 proteins (the number of DEPs identified) randomly sampled from the 770 non-differentially expressed proteins and from all 833 proteins identified by mass spectrometry. Overrepresentation was based on comparison to the reference human genome/proteome. DEP differentially expressed protein, PANTHER PANTHER: Protein ANalysis THrough Evolutionary Relationships

the significantly impacted pathways were differentially expressed.

\section{Differentially expressed proteins with recurring pathway involvement}

Many of the significant pathways featured a small recurring group of DEPs: beta-catenin, alpha-actinin-1, integrin beta-1, integrin alpha-6, caveolin-1, filamin-A, laminin subunit gamma-2, and CD44 antigen (Table 1). Betacatenin and alpha-actinin- 1 contributed to the significance of the "Tight Junction", "Adherens Junction", "Hippo Signaling Pathway", and "Focal Adhesion" pathways. Integrin beta- 1 and integrin alpha- 6 were included in the "Cell Adhesion Molecules", "Small Cell Lung Cancer", and "ECMReceptor Interaction" pathways. Caveolin-1 and filamin A were included in the "Focal Adhesion" and "Proteoglycans in Cancer" pathways. Laminin subunit gamma-2 appeared in the "ECM-Receptor Interaction", "Small Cell Lung Cancer", and "Focal Adhesion" pathways. Finally, CD44 antigen appeared in the "Proteoglycans in Cancer" and
"ECM-Receptor Interaction". Experimental, co-expression, co-occurrence, and homology interactions between DEPs were visualized using STRING (Search Tool for the Retrieval of Interacting Genes/Proteins) [40] (Fig. 3). This plot displays direct interactions between DEPs. Nodes were centered on integrin beta-1, beta-catenin, and caveolin-1, suggesting these proteins have the potential to affect other proteins and may be involved in functional networks.

\section{Differentially expressed proteins and genes in human prostate cancer patient specimens}

To determine the relevance of the 63 DEPs identified in the RC-77 cell line series in human prostate cancer specimens, we extracted protein and RNA expression data from TCGA PRAD cohort. We compared the protein and RNA expression of the 63 DEPs between AfricanAmerican and Caucasian-American prostate cancer specimens; only caveolin-1, beta-catenin, myosin heavy chain-9, serine/arginine-rich splicing factor 1 /splicing 
Table 5 Categorization of differentially expressed proteins according to Gene Ontology Biological Process

\begin{tabular}{|c|c|c|}
\hline \multicolumn{3}{|c|}{ Gene Ontology Biological Process Annotation (Number of Differentially Expressed Proteins) } \\
\hline \multicolumn{3}{|l|}{ Metabolic Process (37) } \\
\hline - eukaryotic translation initiation factor 4B & $\begin{array}{l}\text { - double-stranded RNA-specific adenosine } \\
\text { deaminase }\end{array}$ & $\begin{array}{l}\text { - plasminogen activator inhibitor } 1 \\
\text { RNA-binding protein }\end{array}$ \\
\hline - serotransferrin & - 605 ribosomal protein L6 & - nucleolar RNA helicase 2 \\
\hline - proteasome activator complex subunit 3 & • non-histone chromosomal protein HMG-14 & $\begin{array}{l}\text { - cytosolic acyl coenzyme A thioester } \\
\text { hydrolase }\end{array}$ \\
\hline • phosphoenolpyruvate carboxykinase & • non-histone chromosomal protein HMG-17 & - cytochrome c oxidase subunit 5A \\
\hline - prothymosin alpha & - $40 \mathrm{~S}$ ribosomal protein $\mathrm{S} 11$ & - 40 S ribosomal protein S24 \\
\hline - high mobility group protein HMG-1/HMG-Y & - gamma-interferon-inducible protein 16 & • T-complex protein 1 subunit epsilon \\
\hline - RNA-binding protein EWS & • PDZ and LIM domain protein 1 & • high mobility group protein HMGI-C \\
\hline - calpastatin & - 605 ribosomal protein L35 & - aminopeptidase N \\
\hline - creatine kinase U-type & - myosin heavy chain-9 & • 605 ribosomal protein L10 \\
\hline - S-formylglutathione hydrolase & - hepatoma-derived growth factor & - phosphoserine aminotransferase \\
\hline - thioredoxin domain-containing protein 17 & - S-methyl-5'-thioadenosine phosphorylase & - hydroxyacyl-coenzyme A dehydrogenase \\
\hline • adenosylhomocysteinase & - prefoldin subunit 2 & • caveolin-1 \\
\hline \multicolumn{3}{|c|}{$\begin{array}{l}\text { - putative pre-mRNA-splicing factor ATP-dependent } \\
\text { RNA helicase DHX15 }\end{array}$} \\
\hline \multicolumn{3}{|l|}{ Cellular Process Proteins (23) } \\
\hline - PDZ and LIM domain protein 1 & • type I cytoskeletal keratin 19 & - non-histone chromosomal protein HMG-17 \\
\hline - lamin-B1 & • integrin beta-1 & • CD166 antigen \\
\hline - non-histone chromosomal protein HMG-14 & $\begin{array}{l}\text { - double-stranded RNA-specific adenosine } \\
\text { deaminase }\end{array}$ & - high mobility group protein HMG-1/HMG-Y \\
\hline - myosin heavy chain-9 & - $40 \mathrm{~S}$ ribosomal protein $\mathrm{S} 11$ & • caveolin-1 \\
\hline • vimentin & - 40 S ribosomal protein S24 & - filamin-A \\
\hline - high mobility group protein HMGI-C & • type II cytoskeletal keratin 8 & - hepatoma-derived growth factor \\
\hline • CD59 glycoprotein & - alpha-actinin-1 & $\cdot 14-3-3$ protein sigma \\
\hline - adenosylhomocysteinase & $\begin{array}{l}\text { - putative pre-mRNA-splicing factor } \\
\text { ATP-dependent RNA helicase DHX15 }\end{array}$ & \\
\hline
\end{tabular}

factor 2, double-stranded RNA-specific adenosine deaminase, and X-ray repair cross-complementing protein 5 had both protein and RNA data. X-ray repair crosscomplementing protein 5 protein levels were significantly higher in African-American prostate cancer specimens than in Caucasian-American prostate cancer specimens $(p<0.05)$ (Fig. 4a). The RNA expression of caveolin-1 and myosin heavy chain-9 were significantly downregulated in African-American prostate cancer specimens compared to Caucasian-American prostate cancer specimens $(p<0.01$ and $p<0.05$, respectively) (Fig. 4b). After subtracting mRNA expression levels of non-malignant specimens from human prostate cancer specimens, caveolin-1 and beta-catenin mRNA expression levels were significantly higher in African-American prostate cancer patient specimens compared to CaucasianAmerican prostate cancer specimens (Fig. 5). As indicated by the negative RNA expression value, caveolin-1 was downregulated in African American prostate cancer specimens compared to African American non-malignant control specimens; on the contrary, beta-catenin was upregulated. Therefore, the reduction of caveolin-1 protein levels and the increased protein levels of beta-catenin seen in the tumorigenic RC-77 T/E cells were mirrored in the downregulation of caveolin-1 mRNA and upregulation of beta-catenin mRNA in African-American prostate cancer specimens.

\section{Discussion}

The paired non-malignant and malignant AfricanAmerican prostate epithelial cell lines RC-77 T/E and RC-77 N/E represent one of only a few cell lines derived from African-American prostate cancer patients [30]. E006AA, RC-165 N, and MDA-PCa 2a/2b are other African-American patient-derived cell lines. E006AA also has a highly tumorigenic derivative, E006AA-hT, and an associated stroma cell line, S006AA [27]. While the E006AA-hT model can be used to examine the differences between less and more highly tumorigenic cancers, it does not have a non-malignant paired epithelial 
Table 6 Pathways from the National Cancer Institute-Nature Pathway Interaction Database overrepresented in RC-77 cell lines

\begin{tabular}{|c|c|c|c|}
\hline Pathway Name & Differentially Expressed Proteins in Pathway & $p$-value & $q$-value \\
\hline 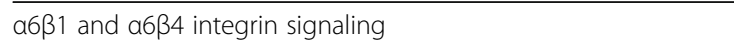 & ITGA6, ITGB1, LAMC2, SFN & $5.75 \mathrm{E}-05$ & $7.88 \mathrm{E}-03$ \\
\hline a4 $\beta 7$ integrin signaling & CD44, ITGB1 & 7.79E-04 & $5.14 \mathrm{E}-02$ \\
\hline a6ß4 integrin-ligand interactions & ITGA6, LAMC2 & $1.18 \mathrm{E}-03$ & $5.14 \mathrm{E}-02$ \\
\hline Arf6 trafficking events & CTNNB1, ITGA6, ITGB1 & $1.50 \mathrm{E}-03$ & $5.14 \mathrm{E}-02$ \\
\hline TGF-beta receptor signaling & CAV1, CTNNB1, PML* & $2.08 \mathrm{E}-03$ & $5.70 \mathrm{E}-02$ \\
\hline mTOR signaling pathway & EIF4B, PML*, SFN & 4.07E-03 & $7.38 \mathrm{E}-02$ \\
\hline$\beta 1$ integrin cell surface interactions & ITGA6, ITGB1, LAMC2 & 4.07E-03 & $7.38 \mathrm{E}-02$ \\
\hline Canonical Wnt signaling pathway & CAV1, CTNNB1 & 4.31E-03 & $7.38 \mathrm{E}-02$ \\
\hline Plexin-D1 signaling & ITGA6, ITGBI & $5.59 \mathrm{E}-03$ & $8.51 \mathrm{E}-02$ \\
\hline Integrin family cell surface interactions & ITGA6, ITGBI & $6.52 \mathrm{E}-03$ & 8.93E-02 \\
\hline BARD1 signaling events & EWSR1*, XRCC5 & $8.58 \mathrm{E}-03$ & 1.07E-01 \\
\hline Syndecan-4-mediated signaling events & ACTN1, ITGB1 & $9.69 \mathrm{E}-03$ & $1.11 \mathrm{E}-01$ \\
\hline Signaling mediated by p38-alpha and p38-beta & KRT19, KRT8 & $1.34 \mathrm{E}-02$ & 1.40E-01 \\
\hline E-cadherin signaling events & CTNNB1 & $1.43 \mathrm{E}-02$ & 1.40E-01 \\
\hline Stabilization and expansion of the E-cadherin adherens junction & ACTN1, CTNNB1 & $1.75 \mathrm{E}-02$ & 1.60E-01 \\
\hline Integrin-linked kinase signaling & ACTN1, CTNNB1 & $1.90 \mathrm{E}-02$ & 1.63E-01 \\
\hline FoxO family signaling & CTNNB1, SFN & $2.21 \mathrm{E}-02$ & $1.78 \mathrm{E}-01$ \\
\hline Direct p53 effectors & CAV1, PML*, SFN & $2.46 \mathrm{E}-02$ & 1.87E-01 \\
\hline Caspase cascade in apoptosis & $\angle M N B 1, V I M$ & $2.79 \mathrm{E}-02$ & $2.01 \mathrm{E}-01$ \\
\hline Co-regulation of androgen receptor activity & CTNNB1, XRCC5 & 3.32E-02 & 2.17E-01 \\
\hline Signaling events mediated by focal adhesion kinase & ACTN1, ITGB1 & $3.32 \mathrm{E}-02$ & 2.17E-01 \\
\hline Validated targets of C-MYC transcriptional repression & ITGA6, ITGBI & 4.27E-02 & $2.54 \mathrm{E}-01$ \\
\hline Signaling events mediated by VEGFR1 and VEGFR2 & CAV1, CTNNB1 & 4.27E-02 & $2.54 \mathrm{E}-01$ \\
\hline p73 transcription factor network & $\mathrm{PML}^{*}, \mathrm{SFN}$ & 4.88E-02 & $2.79 \mathrm{E}-01$ \\
\hline
\end{tabular}

Proteins in bold font were upregulated in RC-77 T/E. Proteins in italic font were downregulated in RC-77 T/E. *Protein found in RC-77 T/E only. $P$-values were calculated using a hypergeometric cumulative distribution function. Q-value is the $p$-value corrected for multiple hypotheses testing using the Benjamini-Hochberg method. ACTN1 alpha-actinin-1, CAV1 caveolin-1, CD44 CD44 antigen, CTNNB1 beta-catenin, EIF4B eukaryotic translation initiation factor 4B, EWSR1 RNA-binding protein EWS, ITGA6 integrin alpha-6, ITGB1 integrin beta-1, KRT8 type II cytoskeletal keratin 8, KRT19= type I cytoskeletal keratin 19, LAMC2 laminin subunit gamma-2, LMNB1 lamin-B1, PML protein PML, SFN 14-3-3 protein sigma, VIM vimentin, XRCC5 X-ray repair cross-complementing protein 5

cell line. The $\mathrm{RC}-165 \mathrm{~N}$ cell line is unique because it was derived from benign prostate tissue of an AfricanAmerican male and was immortalized by telomerase [41]. This cell line is useful for understanding the functions of the androgen receptor in prostate epithelial cells. MDA-PCa $2 \mathrm{a} / 2 \mathrm{~b}$ cells are tumorigenic but differ in vivo and in vitro. These cell lines are a useful androgen sensitive model, but, unlike RC-77 cells, they do not have a paired non-malignant cell line from the same patient [29]. As RC-77 cell lines have epithelial-like characteristics, have functioning androgen receptors, and are immortalized with both a malignant and non-malignant pair, they represent a promising model for studying prostate cancer.

Here, we report the global proteomic characterization of RC-77 T/E and RC-77 N/E cell lines. Since RC-77 T/ $\mathrm{E}$ cells are tumorigenic and $\mathrm{RC}-77 \mathrm{~N} / \mathrm{E}$ cells are not, we analyzed DEPs between the two phenotypes. In overrepresentation analysis, GSEA, and SPIA, we consistently found that beta-catenin, alpha-actinin-1, integrin beta-1, integrin alpha-6, caveolin-1, laminin subunit gamma-2, CD44 antigen, and filamin-A expression levels contributed to the significance of the pathways highlighted in this report. Each of these proteins has structural roles or roles in cell adhesion, which explains why structural proteins were more prevalent among DEPs than could be expected by random chance and why many overrepresented pathways were related to cell adhesion (cell-cell or cell-matrix) or integrin signaling. Beta-catenin forms a complex with E-cadherin at adherens junctions to mediate cell-cell adhesion [42]. Alpha-actinin-1 forms focal adhesions, adherens junctions, tight junctions, and hemidesmosomes; forms cell-cell or cell-matrix contacts; and plays a scaffolding role for the cytoskeleton in a variety of signaling pathways [43]. Integrins interact with extracellular matrix (ECM) components to form cellmatrix attachments and propagate extracellular signals [44]. Caveolin-1 is an important component of caveolae, 
Table 7 Enriched gene sets in RC-77 T/E and RC-77 N/E cell lines

\begin{tabular}{|c|c|c|c|c|}
\hline Pathway (Size) & NES & $p$-value & $q$-value & Proteins Contributing to Enrichment \\
\hline KEGG: Tight Junction (16) & 2.064 & $0.00 E+00$ & $3.41 \mathrm{E}-03$ & $\begin{array}{l}\text { alpha-actinin-1*, alpha-actinin- } 4^{*} \text {, alpha-catenin, beta-catenin*, casein } \\
\text { kinase II subunit beta, myosin heavy chain-9*, Src substrate cortactin* }\end{array}$ \\
\hline KEGG: Cell Adhesion Molecules (6) & -1.836 & $0.00 \mathrm{E}+00$ & $1.34 \mathrm{E}-02$ & CD166 antigen, integrin alpha- 6 , integrin beta- 1 \\
\hline KEGG: Hippo Signaling Pathway (9) & 1.797 & $3.98 \mathrm{E}-03$ & 2.73E-02 & $\begin{array}{l}\text { alpha-catenin*, beta-catenin*, } 14-3-3 \text { protein beta/alpha, } 14-3-3 \\
\text { protein theta, } 14-3-3 \text { protein zeta/delta }\end{array}$ \\
\hline $\begin{array}{l}\text { KEGG: Transcriptional Misregulation in } \\
\text { Cancer (9) }\end{array}$ & 1.733 & $1.54 \mathrm{E}-02$ & 4.09E-02 & $\begin{array}{l}\text { high mobility group protein HMGI-C, junction plakoglobin*, } \\
\text { protein PML, RNA-binding protein EWS, RNA-binding protein FUS }\end{array}$ \\
\hline KEGG: Adherens Junction (12) & 1.704 & $1.27 \mathrm{E}-02$ & 4.87E-02 & $\begin{array}{l}\text { alpha-actinin-1*, alpha-actinin-4*, alpha-catenin*, beta-catenin*, } \\
\text { epidermal growth factor receptor, casein kinase II subunit beta }\end{array}$ \\
\hline BioCarta: ChREBP2 Pathway (7) & 1.695 & $1.01 \mathrm{E}-02$ & 8.11E-02 & $\begin{array}{l}\text { 14-3-3 protein beta/alpha, } 14-3-3 \text { protein theta, } 14-3-3 \text { protein } \\
\text { zeta/delta, fatty acid synthase }\end{array}$ \\
\hline KEGG: Cell Cycle (9) & 1.627 & $2.49 \mathrm{E}-02$ & 9.07E-02 & $\begin{array}{l}\text { DNA-dependent protein kinase catalytic subunit, DNA replication } \\
\text { licensing factor MCM6, 14-3-3 protein beta/alpha, } \\
\mathbf{1 4 - 3 - 3} \text { protein sigma, 14-3-3 protein theta, 14-3-3 protein zeta/delta, }\end{array}$ \\
\hline KEGG: ECM-Receptor Interaction (8) & -1.557 & $6.09 \mathrm{E}-03$ & $1.57 \mathrm{E}-01$ & $\begin{array}{l}\text { CD44 antigen, integrin alpha-2, integrin alpha-3, integrin alpha-6, } \\
\text { integrin beta-1, integrin beta-4, laminin subunit beta-3, } \\
\text { laminin subunit gamma-2 }\end{array}$ \\
\hline KEGG: Small Cell Lung Cancer (7) & -1.488 & $5.20 \mathrm{E}-02$ & 1.87E-01 & $\begin{array}{l}\text { integrin alpha-2, integrin alpha-3, integrin alpha-6, integrin beta-1, } \\
\text { laminin subunit beta-3, laminin subunit gamma-2 }\end{array}$ \\
\hline $\begin{array}{l}\text { KEGG: Complement and Coagulation } \\
\text { Cascades (5) }\end{array}$ & -1.441 & $5.08 \mathrm{E}-02$ & $2.02 \mathrm{E}-01$ & $\begin{array}{l}\text { alpha-1-antitrypsin, alpha-2-macroglobulin, complement C3, } \\
\text { CD59 glycoprotein, tissue factor }\end{array}$ \\
\hline
\end{tabular}

Positive enrichment scores correspond to enrichment in RC-77 T/E samples. Negative enrichment scores correspond to enrichment in RC-77 N/E samples. Bolded proteins were differentially expressed ( $q<0.1$, Wilcoxon rank-sum test). *Carries a "Structural" or "Cytoskeletal" annotation in PANTHER. ChREBP2 carbohydrate responsive element binding protein, ECM extracellular matrix, KEGG Kyoto Encyclopedia of Genes and Genomes, NES normalized enrichment score (normalized to size of the pathway); $p$-value $=$ probability of significance after permutation, $q$-value $=$ false discovery rate-adjusted $p$-value; size $=$ total number of genes in pathway

which are involved in molecular transport, cell adhesion, motility, and signal transduction [45, 46]. Laminin forms part of the basement membrane in some epithelial tissues and functions in adhesion, migration, invasion, and differentiation [47]. The glycoprotein CD44 antigen mediates cell adhesion and cytoskeleton binding through interactions with other proteins such as ankryin and ezrin, radixin, and moesin (ERM) proteins [48] and mediates hyaluronan-stimulated proliferation, apoptosis inhibition, cell motility, invasion [49]. Filamin-A cross-links actin filaments and serves as a scaffolding protein to organize the actin cytoskeleton [50], which affects cell motility, migration, and signaling [51].

Furthermore, expression levels of beta-catenin, caveolin1 , integrin beta-1, integrin alpha-6, CD44 antigen, and alpha-actinin- 1 have been shown to differ by race. Here, we have shown higher beta-catenin protein levels in malignant RC-77 T/E cells compared to RC-77 N/E cells and that its mRNA is upregulated in African-American prostate cancer specimen compared to CaucasianAmerican specimen after subtracting the mRNA expression of race-specific non-malignant controls. These results are consistent with previous reports that betacatenin is highly elevated in African-American prostate tumors compared to Caucasian tumors [16, 52]. Integrin alpha- 6 and integrin beta- 1 were downregulated in RC$77 \mathrm{~T} / \mathrm{E}$ cells compared to RC-77 N/E cells, and integrins have been shown to be downregulated in AfricanAmerican prostate cancer tissue compared to Caucasian specimens [12]. Thus, in these aspects, RC-77 T/E cells reflect in vivo characteristics of African-American prostate cancer and may be useful in the study of malignant transformation in African-American prostate tumors. While alpha-actinin-1 was upregulated in malignant RC-77 T/E

Table 8 Significantly inhibited pathways in RC-77 T/E cell lines

\begin{tabular}{llllll}
\hline Name (KEGG ID) & NDE & pNDE & PPERT & pG & pGFdr \\
\hline Focal Adhesion (hsa04510) & 7 & $9.61 \mathrm{E}-04$ & $2.00 \mathrm{E}-02$ & $2.28 \mathrm{E}-04$ & $9.34 \mathrm{E}-03$ \\
Small Cell Lung Cancer (hsa05222) & 3 & $1.17 \mathrm{E}-02$ & $1.40 \mathrm{E}-02$ & $1.59 \mathrm{E}-03$ & $2.46 \mathrm{E}-02$ \\
Proteoglycans in Cancer (hsa05205) & 6 & $1.35 \mathrm{E}-03$ & $1.78 \mathrm{E}-01$ & $2.25 \mathrm{E}-03$ & $2.46 \mathrm{E}-02$ \\
ECM-Receptor Interaction (hsa04512) & 4 & $1.67 \mathrm{E}-03$ & $1.55 \mathrm{E}-01$ & $2.40 \mathrm{E}-03$ & $2.46 \mathrm{E}-02$ \\
\hline
\end{tabular}

$E C M$ extracellular matrix, NDE number of differentially expressed elements, $p G$ global probability, $p G F d r$ false discovery rate-adjusted global probability, PNDE overrepresentation probability, PPERT, perturbation probability 


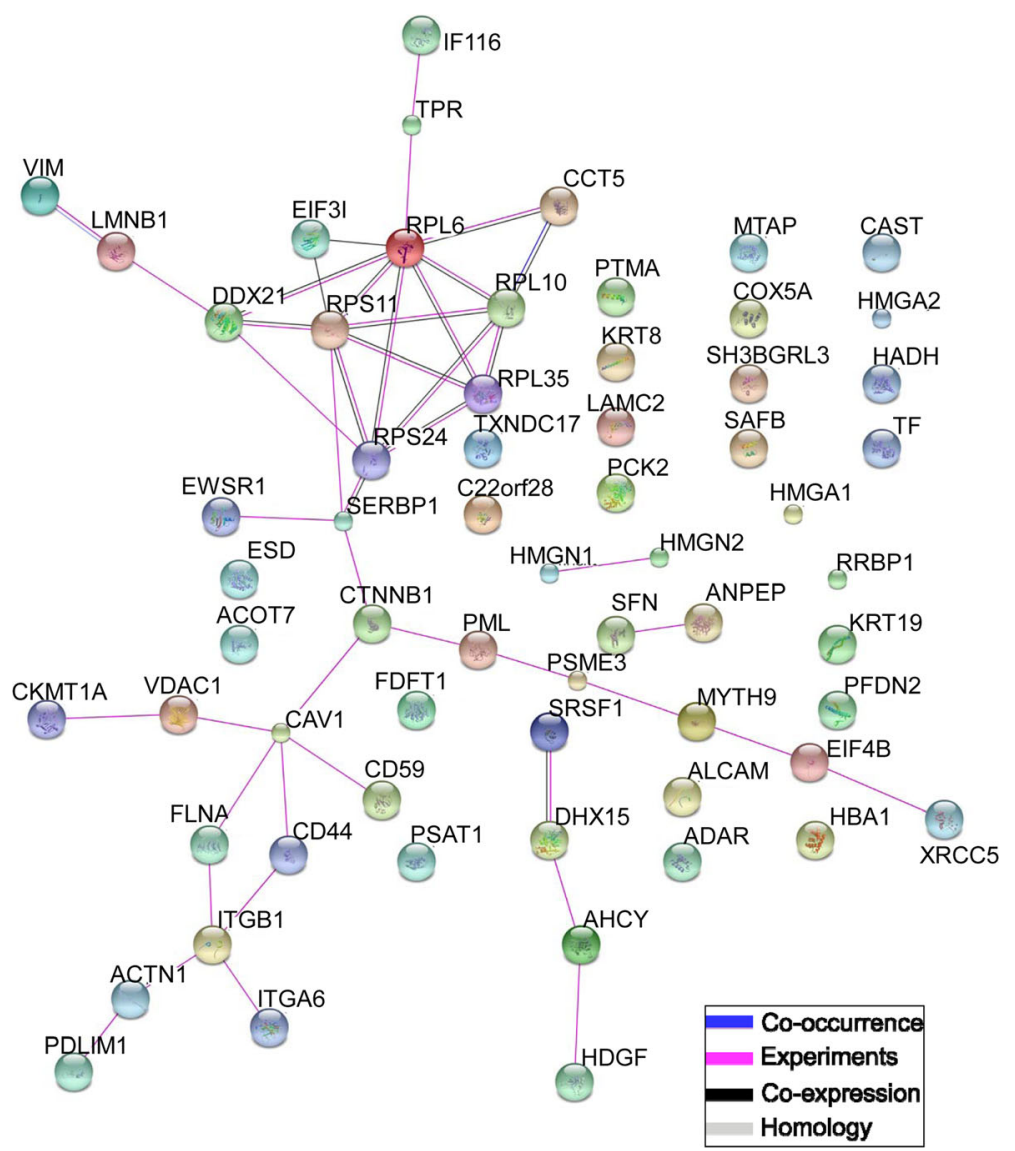

Fig. 3 Functional associations between differentially expressed proteins in RC-77 T/E and RC-77 N/E cell lines. STRING (Search Tool for the Retrieval of Interacting Genes/Proteins) was used to visualize a network of functional associations between differentially expressed proteins. Interactions were limited to only those supported by experimental evidence, co-expression or co-occurrence data, and gene homology data. See Table 1 for the full names of proteins abbreviated here. Nodes centered on integrin beta-1, beta-catenin, and caveolin-1, suggesting these proteins have the potential to affect other proteins and may be involved in functional networks

cells, it was downregulated in African-American prostate cancer tissue compared to Caucasian specimens [12]. Our results also showed that caveolin-1 protein level was lower in malignant RC-77 T/E cells than nonmalignant RC-77 N/E cells and that its mRNA expression was downregulated in African-American prostate cancer patient specimen compared to non-malignant African-American prostate specimen. After subtracting race-specific non-malignant RNA expression, caveolin-1 mRNA expression was higher in African-American prostate cancer patient specimens than in specimens from Caucasian-American patients. This result is in agreement with another study reporting elevated caveolin-1 protein expression in African-American prostate cancer specimens compared to Caucasian-American specimens [53]. African-American prostate cancer patients were also found to have higher rates of methylation of the CD44 gene [54], which was downregulated in malignant RC$77 \mathrm{~T} / \mathrm{E}$ cells in this study.
To understand how differential expression of betacatenin, caveolin-1, integrin beta-1, integrin alpha-6, CD44 antigen, and alpha-actinin-1 in RC-77 T/E cells may be related to phenotypic differences between $\mathrm{RC}$ $77 \mathrm{~T} / \mathrm{E}$ and RC-77 N/E cell lines, we looked at the interactions between the DEPs using both STRING (to visualize direct interactions) and pathway analyses. First, the STRING network map revealed beta-catenin, integrin beta-1, and caveolin-1 in nodal positions, meaning these proteins may interact with several other DEPs in our dataset and may be a key regulator of the pathways highlighted in our results. For example, interaction between filamin-A and integrin beta-1 or caveolin-1 promotes migration, cell spreading, or metastasis, while interaction with other proteins results in inhibition of metastasis [51]. While filamin-A was upregulated in RC$77 \mathrm{~T} / \mathrm{E}$ cells, integrin beta-1, caveolin-1 and vimentin, three of its binding partners that promote metastasis, were significantly downregulated. This is congruent 
a TCGA DEPs Expression by Race

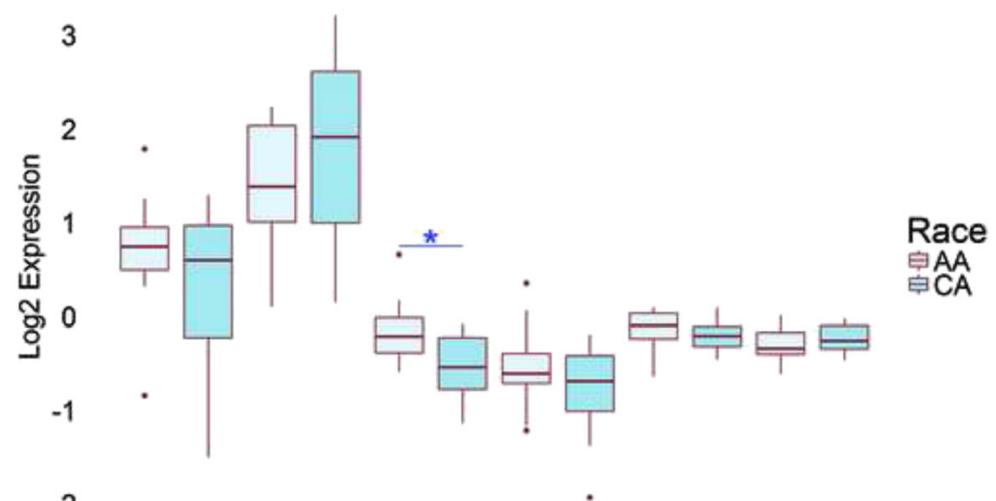

$-2$

CTNNB1 CAV1 XRCC5 MYH9 SRSF1 ADAR

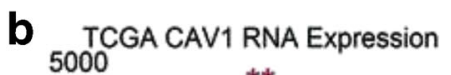

TCGA MYH9 RNA Expression
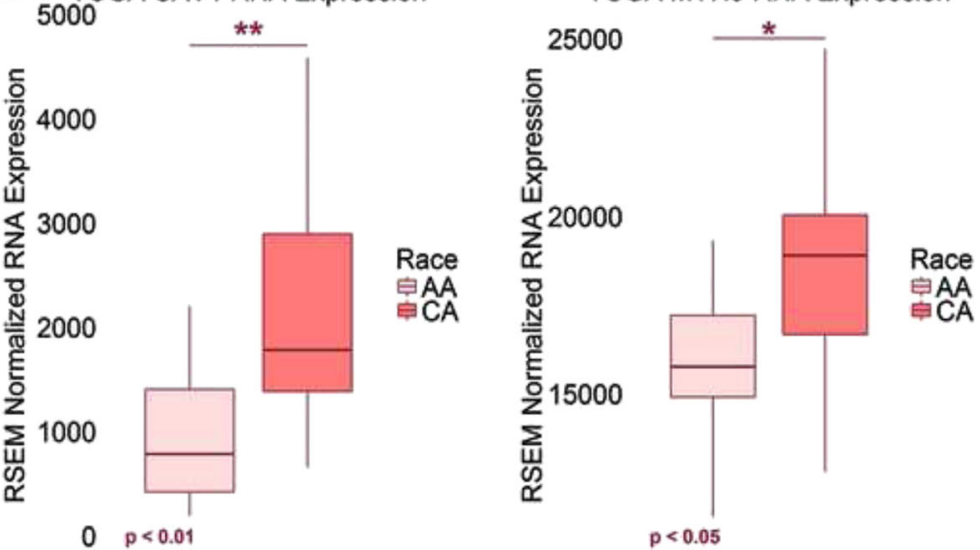

Fig. 4 Expression of differentially expressed proteins by race in age- and stage-matched human prostate cancer specimens. In 12 age-and stage-matched prostate cancer specimen pairs extracted from TCGA without subtracting the non-malignant controls, (A) XRCC5 protein was found to be significantly different $(p<0.05)$ between African-American and Caucasian-American prostate cancer specimens and (B) RNA expression of CAV1 and MYH9 were found to be significantly different ( $p<0.01$ and $<0.05$, respectively) between African-American and Caucasian-American prostate cancer specimens. The $p$-values were generated using the "t.test" function in R. AA = African-American; $\mathrm{ADAR}=$ double-stranded RNA-specific adenosine deaminase; $\mathrm{CA}=$ Caucasian-American; CAV1 = caveolin-1; CTNNB1 = beta-catenin; MYH9 = myosin heavy chain-9; SRSF1 = serine/arginine-rich splicing factor 1; TCGA = The Cancer Genome Atlas; XRCC5 = X-ray repair cross-complementing protein 5

with our knowledge that RC-77 T/E cells are derived from early stage primary prostate cancer (Gleason score 7) and are not metastatic [30]. Second, pathway analyses revealed that a common thread among the significant pathways was the inclusion of structural proteins, which could each be linked to invasion or migration of cells. "Tight Junction" and "Adherens Junction" pathways were enriched specifically in RC$77 \mathrm{~T} / \mathrm{E}$ cells. Tight junctions are composed of claudin proteins, junctional adhesion molecules, integral membrane proteins, and cytoplasmic proteins, while adherens junctions are formed of cadherins and catenins [55]. Both hold together adjacent cells and help with structural and mechanical cell-cell integrity. The disruption of cell adhesion can facilitate the metastasis of tumor cells to secondary locations and lead to cell growth unchecked by contact inhibition [56]. The "Focal Adhesions" and "Proteoglycans in Cancer" pathways were significantly inhibited in RC-77 T/E cells. Proteoglycans in the tumor microenvironment associate with ECM proteins and affect proliferation, adhesion, and metastasis [57]. While the significance of the "Small Cell Lung Cancer" KEGG pathway may seem odd, it was highlighted in this dataset because of the role of ECM-receptor interactions and focal adhesions in cancer progression (see Additional file 10). "Cell Adhesion Molecules" and "ECM-Receptor Interaction" pathways, which were enriched in RC-77 N/E cells according to GSEA and shown to be significant by SPIA, were primarily flagged because of integrin expression. 


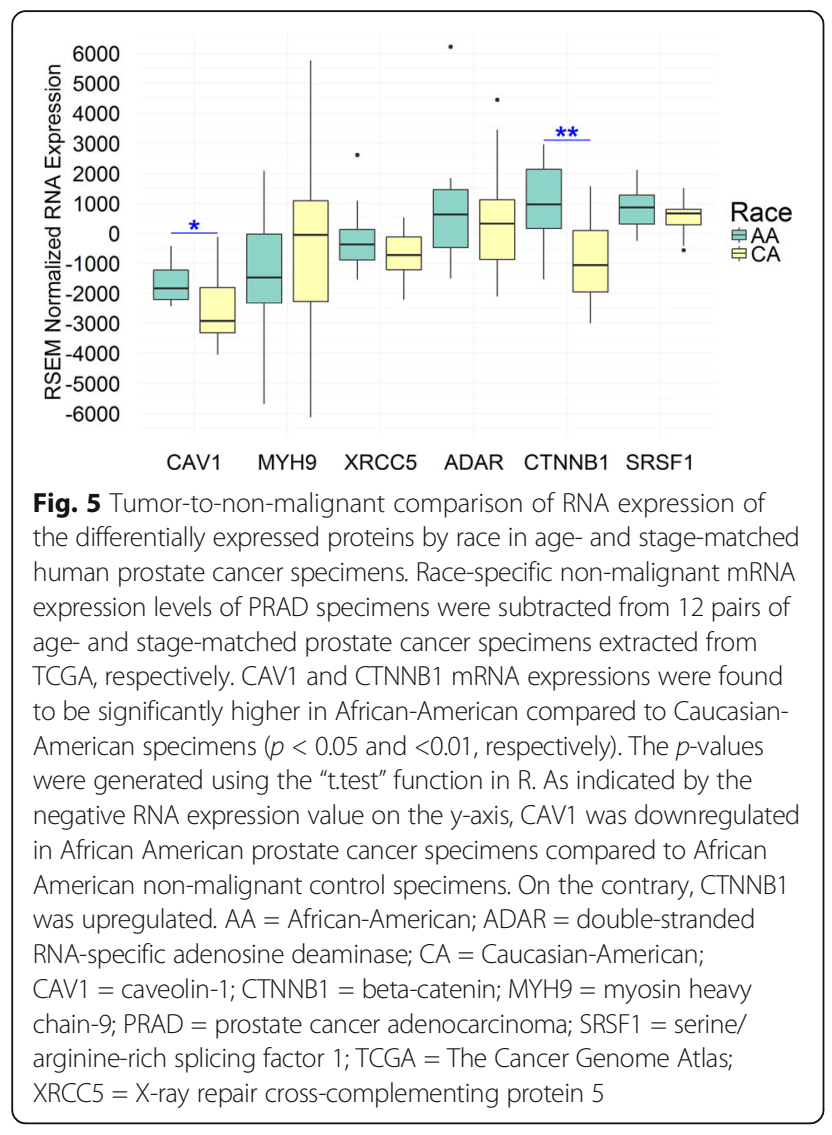

\section{Conclusion}

We detected 63 differentially expressed proteins between the malignant RC-77 T/E and the non-malignant RC$77 \mathrm{~N} / \mathrm{E}$ cell lines, with 18 proteins uniquely detected in RC-77 T/E cells and 2 proteins uniquely detected in RC-77 N/E cells. The STRING network map revealed beta-catenin, integrin beta-1, and caveolin-1 in nodal positions, suggesting these proteins interact with several other DEPs and may be key regulators of the identified pathways. The "Tight Junction", "Cell Adhesion Molecules", "Adherens Junction", "ECM-Receptor interaction", "Focal Adhesion", and "Proteoglycans in Cancer" pathways were shown to correlate with either RC-77 T/E or RC77 N/E cells. Because structural proteins were overrepresented among DEPs and because several of the DEPs common to the significant pathways identified are structural proteins or have a structural role, our findings suggest that structural proteins may significantly contribute to the phenotypic differences between RC-77 T/E and RC-77 N/E cell lines. Based on data from both human prostate cell lines and limited patient specimens, our results indicate that differential expression of caveolin-1 and beta-catenin may be race- and prostate cancer-specific. A larger number of patients will be required to verify these findings. Although the RC-77 cell model may not be representative of all African-American prostate cancer due to tumor heterogeneity, it is a resource for studying prostate cancer initiation and progression.

\section{Additional files}

Additional file 1: Operating Parameters for Mass Spectrometry Experiments. This text file provides the technical operating parameters for the mass spectrometry experiments

Additional file 2: MA Plot. This MA plot shows the data before (a) and after (b) transformation. The variances of the data remained similar before and after transformation, except for the larger average effects (> 40 in original scale). (TIFF $347 \mathrm{~kb}$ )

Additional file 3: KEGG Pathways Selected for Inclusion in All Pathway Analyses. These are the KEGG pathways used in Gene Set Enrichment Analysis and Signaling Pathway Impact Analysis. Pathways likely to have little relevance to prostate cancer (e.g., parasitic, bacterial, and viral infectious diseases; substance dependencies; and specific immune, neurodegenerative, and cardiovascular diseases) were excluded from the set

Additional file 4: TCGA PRAD DEPs Protein and mRNA Expression Data. This spreadsheet contains the patient demographics, tumor characteristics, and protein and mRNA expression data for the 24 age- and stage-matched African-American and Caucasian-American tumors used in this study. Additional sheets present the data of patients used for the non-malignant comparison and the expression values after subtracting the race-specific averaged values from the tumor expression values. (XLSX 23 kb)

Additional file 5: Proteins Identified in RC77T/E and RC-77 N/E Cell Lines. This table lists all protein assignments and raw spectral counts obtained by high-resolution electrospray tandem mass spectrometry (nLC-ESI-LIT-Orbitrap) for all biological replicates.

Additional file 6: Processed Proteomics Data. This table contains the working dataset formed after processing the raw data. Processing included summing isoform data, rounding expression data up to the nearest whole number, and calculating $\log ^{2}$ fold change ratios

Additional file 7: Reproducibility of Protein Fold Changes among Biological Replicates. This figure shows the $\log _{2}$ fold changes of corresponding biological replicates among RC-77 T/E and RC-77 N/E cell lines. The variations are well-controlled, as the majority of the proteins having fold changes less than 2 in both normal and tumor cell lines. (PDF $936 \mathrm{~kb}$ )

Additional file 8: Additional Analysis on Reproducibility of Protein Fold Changes between Paired Malignant and Non-Malignant Replicates. The differential expressions are stable across different pairs of tumor and nonmalignant cell lines. (PNG $695 \mathrm{~kb}$ )

Additional file 9: Complete Gene Set Enrichment Analysis Results. This table lists the enriched gene sets identified from KEGG, BioCarta, and Reactome databases using Gene Set Enrichment Analysis. Positive enrichment scores correspond to enrichment in the malignant samples (RC-77 T/E). Negative enrichment scores correspond to enrichment in the non-malignant samples (RC-77 N/E). SIZE = total number of genes in pathway, ES = enrichment score, NES = normalized enrichment score, NOM p-val = unadjusted probability of enrichment, FDR q-val = false discovery rate-adjusted probability. Additional file 10: Complete Signaling Pathway Impact Analysis Results. This table presents the complete results of Signaling Pathway Impact Analysis. For each pathway, a link to a pathway diagram highlighting differentially expressed proteins in red is provided. ID = KEGG ID, pSize = pathway size, $\mathrm{NDE}=$ number of differentially expressed proteins in pathway, $\mathrm{pNDE}=$ probability of overrepresentation, $\mathrm{tA}=$ total accumulated perturbation, PPERT = probability of perturbation, $\mathrm{pG}=$ combined global probability of overrepresentation and perturbation, $\mathrm{pGFdr}=$ false-discovery rate-adjusted global probability, pGFWER = familywise error rate-adjusted global probability

\section{Abbreviations}

DEP: Differentially expressed protein; ECM: Extracellular matrix; FDR: False discovery rate; GO: Gene Ontology; GSEA: Gene Set Enrichment Analysis; KEGG: Kyoto Encyclopedia of Genes and Genomes; PANTHER: Protein ANalysis THrough Evolutionary Relationships; pGFdr: False discovery rate- 
adjusted global probability; PRAD: Prostate adenocarcinoma; SPIA: Signaling Pathway Impact Analysis; STRING: Search Tool for the Retrieval of Interacting Genes/Proteins; TCGA: The Cancer Genome Atlas

\section{Acknowledgements}

The authors wish to thank Honghe Wang for cell culture, Kate Calvin and Rakesh Singh of the Florida State University Translational Science Laboratory for mass spectrometry assistance, and Ariana K. von Lersner and Charles J. Robbins for technical assistance.

\section{Funding}

This work was in part supported by the Leslie N. Wilson-Delores Auzenne Graduate Assistantship for Minorities from the Graduate School at Florida State University to JSM for study design, the collection, analysis, and interpretation of data, and writing the manuscript; and in part by grants from Florida State University and an Endowed Chair Professorship in Cancer Research from anonymous donors to QXAS for study design, directing the research, and writing the manuscript. This work was in part supported by grants from the Department of Defense Prostate Cancer Research Program (PC120913), NIH/NIMHD (G12 RR03059-21A1), NIH/NCI (R21 CA188799-01), and $\mathrm{NIH/NCI} \mathrm{(U54} \mathrm{CA118623)} \mathrm{to} \mathrm{CCY} \mathrm{for} \mathrm{growing}$ and maintaining the cell lines and writing the manuscript. The funding bodies played no direct role in the study design, data collection, data analysis, data interpretation or the writing of the manuscript.

\section{Availability of data and materials}

The dataset supporting the conclusions of this article is included within the article and its additional files.

\section{Authors' contributions}

JSM participated in the study design, isolated and prepared proteins for proteomic analysis, performed data analysis (including processing, statistical calculations, programming, and pathway analyses), and prepared the manuscript. KAV performed bioinformatics analyses and helped edit the manuscript. JW performed bioinformatics analyses of patient tissue specimens from TCGA. KY contributed to the programming and statistical analyses. CCY cultured the African-American cell lines and helped revise the manuscript. QXAS conceived of the study, directed the research, analyzed the data, and helped write and revise the manuscript. All authors read and approved the final manuscript.

\section{Ethics approval and consent to participate}

Not applicable. This work used existing and de-identified human cell lines established many years ago as reported in the cited reference [30] by Theodore et al. The use of these cell lines for this study was approved by the institutional review board (IRB) at Tuskegee University. This work does not involve in making any new cell lines. This Human Subjects Research falls under Exemption 4 as described in 45 CFR § 46.101 (b)(4) according to the U.S. Department of Health \& Human Services. "Research involving the collection or study of existing data, documents, records, pathological specimens, or diagnostic specimens, if these sources are publically available or if the information is recorded by the investigator in such a manner that subjects cannot be identified, directly or through identifiers linked to the subjects."

\section{Consent for publication}

Not applicable.

\section{Competing interests}

The authors declare no competing interests.

\section{Publisher's Note}

Springer Nature remains neutral with regard to jurisdictional claims in published maps and institutional affiliations.

\section{Author details}

'Department of Chemistry and Biochemistry and Institute of Molecular Biophysics, Florida State University, 95 Chieftan Way, Tallahassee, FL 32306-4390, USA. 'Department of Biology and Center for Cancer Research, Tuskegee University, Tuskegee, AL 36088, USA. ${ }^{3}$ Department of Biostatistics Unit 1411, University of Texas MD Anderson Cancer Center, Houston, TX 77030-1402, USA.
Received: 28 December 2015 Accepted: 28 June 2017 Published online: 11 July 2017

\section{References}

1. Siegel RL, Miller KD, Jemal A. Cancer statistics, 2015. CA Cancer J Clin. 2015;65:5-29.

2. Platz EA, Rimm EB, Willett WC, Kantoff PW, Giovannucci E. Racial variation in prostate cancer incidence and in hormonal system markers among male health professionals. J Natl Cancer Inst. 2000:92:2009-17.

3. Wells TS, Bukowinski AT, Smith TC, Smith B, Dennis LK, Chu LK, et al. Racial differences in prostate cancer risk remain among US servicemen with equal access to care. Prostate. 2010;70:727-34.

4. Karami S, Young HA, Henson DE. Earlier age at diagnosis: another dimension in cancer disparity? Cancer Detect Prev. 2007;31:29-34.

5. Chornokur G, Dalton K, Borysova ME, Kumar NB. Disparities at presentation, diagnosis, treatment, and survival in African American men, affected by prostate cancer. Prostate. 2011;71:985-97.

6. American Cancer Society. Cancer Facts \& Figures 2015. Atlanta: American Cancer Society; 2015.

7. Zhang H, Messing EM, Travis LB, Hyrien O, Chen R, Milano MT, et al. Age and racial differences among PSA-detected (AJCC stage T1CNOMO) prostate cancer in the U.S.: a population-based study of 70,345 men. Front Oncol. 2013;3:312.

8. Tsivian M, Banez LL, Keto CJ, Abern MR, Qi P, Gerber L, et al. African-American men with low-grade prostate cancer have higher tumor burdens: results from the Duke prostate Center. Prostate Cancer Prostatic Dis. 2013:16:91-4.

9. Sanchez-Ortiz RF, Troncoso P, Babaian RJ, Lloreta J, Johnston DA, Pettaway CA. African-American men with nonpalpable prostate cancer exhibit greater tumor volume than matched white men. Cancer. 2006;107:75-82.

10. Farrell J, Petrovics G, McLeod DG, Srivastava S. Genetic and molecular differences in prostate carcinogenesis between African American and Caucasian American men. Int J Mol Sci. 2013;14:15510-31.

11. Farrell J, Young D, Chen Y, Cullen J, Rosner IL, Kagan J, et al. Predominance of ERG-negative high-grade prostate cancers in African American men. Mol Clin Oncol. 2014;2:982-6.

12. Kinseth MA, Jia Z, Rahmatpanah F, Sawyers A, Sutton M, Wang-Rodriguez J, et al. Expression differences between African American and Caucasian prostate cancer tissue reveals that stroma is the site of aggressive changes. Int J Cancer. 2013;134:81-91.

13. Powell IJ, Dyson G, Land S, Ruterbusch J, Bock CH, Lenk S, et al. Genes associated with prostate cancer are differentially expressed in African American and European American men. Cancer Epidemiol Biomark Prev. 2013;22:891-7.

14. Reams RR, Agrawal D, Davis MB, Yoder S, Odedina FT, Kumar N, et al. Microarray comparison of prostate tumor gene expression in AfricanAmerican and Caucasian American males: a pilot project study. Infect Agent Cancer. 2009:4:53.

15. Wallace TA, Prueitt RL, Yi M, Howe TM, Gillespie JW, Yfantis HG, et al. Tumor immunobiological differences in prostate cancer between African-American and European-American men. Cancer Res. 2008;68:927-36.

16. Venkatesh K, Lajwanti D, Kiran SP, Raje DV, Nayarisseri A. Differentially expressed genes in tumors of prostate cancer in American patients with European and African origin. J Pharm Res. 2013;6:583-8.

17. Theodore SC, Davis M, Zhao F, Wang H, Chen D, Rhim J, et al. MicroRNA profiling of novel African American and Caucasian prostate cancer cell lines reveals a reciprocal regulatory relationship of miR-152 and DNA methyltranferase 1. Oncotarget. 2014:5:3512-25.

18. Taksler GB, Keating NL, Cutler DM. Explaining racial differences in prostate cancer mortality. Cancer. 2012;118:4280-9.

19. van Bokhoven A, Varella-Garcia M, Korch C, Johannes WU, Smith EE, Miller $\mathrm{HL}$, et al. Molecular characterization of human prostate carcinoma cell lines. Prostate. 2003:57:205-25.

20. Wolf M, Mousses S, Hautaniemi S, Karhu R, Huusko P, Allinen M, et al. Highresolution analysis of Gene copy number alterations in human prostate cancer using CGH on cDNA microarrays: impact of copy number on Gene expression. Neoplasia. 2004;6:240-7.

21. Bennett NC, Hooper JD, Johnson DW, Gobe GC. Expression profiles and functional associations of endogenous androgen receptor and caveolin-1 in prostate cancer cell lines. Prostate. 2014;74:478-87.

22. Meehan KL, Sadar MD. Quantitative profiling of LNCaP prostate cancer cells using isotope-coded affinity tags and mass spectrometry. Proteomics. 2004;4:1116-34 
23. Dozmorov MG, Hurst RE, Culkin DJ, Kropp BP, Frank MB, Osban J, et al. Unique patterns of molecular profiling between human prostate cancer LNCaP and PC-3 cells. Prostate. 2009;69:1077-90.

24. Myung JK, Sadar MD. Large scale phosphoproteome analysis of LNCaP human prostate cancer cells. Mol BioSyst. 2012;8:2174-82.

25. Glen A, Evans CA, Gan CS, Cross SS, Hamdy FC, Gibbins J, et al. Eight-plex iTRAQ analysis of variant metastatic human prostate cancer cells identifies candidate biomarkers of progression: an exploratory study. Prostate. 2010; 70:1313-32.

26. Koochekpour S, Maresh GA, Katner A, Parker-Johnson K, Lee T, Hebert FE, et al. Establishment and characterization of a primary androgen-responsive African-American prostate cancer cell line, E006AA. Prostate. 2004;60:141-52.

27. Koochekpour S, Willard SS, Shourideh M, Ali S, Liu C, Azabdaftari G, et al. Establishment and characterization of a highly tumorigenic African American prostate cancer cell line, E006AA-hT. Int J Biol Sci. 2014;10:834-45.

28. Gu Y, Kim KH, Ko D, Srivastava S, Moul JW, McLeod DG, et al. Androgen and androgen receptor antagonist responsive primary African-American benign prostate epithelial cell line. Anticancer Res. 2005;25:1-8.

29. Navone NM, Olive M, Ozen M, Davis R, Troncoso P, Tu SM, et al. Establishment of two human prostate cancer cell lines derived from a single bone metastasis. Clin Cancer Res. 1997:3:2493-500.

30. Theodore S, Sharp S, Zhou J, Turner T, Li H, Miki J, et al. Establishment and characterization of a pair of non-malignant and malignant tumor derived cell lines from an African American prostate cancer patient. Int J Oncol. 2010;37:1477-82

31. Theodore SC, Rhim JS, Turner T, Yates C. MiRNA 26a expression in a novel panel of African American prostate cancer cell lines. Ethn Dis. 2010;20:S196-00.

32. Reams R, Kalari K, Wang H, Odedina FT, Soliman KF, Yates C. Detecting gene-gene interactions in prostate disease in African American men. Infect Agent Cancer. 2011;6:S1.

33. Siddique HR, Parray A, Zhong W, Karnes RJ, Bergstralh EJ, Koochekpour S, et al. BMI1, stem cell factor acting as novel serum-biomarker for Caucasian and African-American prostate cancer. PLoS One. 2013;8:e52993.

34. Parray A, Siddique HR, Kuriger JK, Mishra SK, Rhim JS, Nelson HH, et al. ROBO1, a tumor suppressor and critical molecular barrier for localized tumor cells to acquire invasive phenotype: study in African-American and Caucasian prostate cancer models. Int J Cancer. 2014;135:2493-506.

35. R Core Team. R: A language and environment for statistical computing. 2014. Version 3.1.2

36. Mi H, Muruganujan A, Thomas PD. PANTHER in 2013: modeling the evolution of gene function, and other gene attributes, in the context of phylogenetic trees. Nucleic Acids Res. 2013;41:D377-86.

37. Schaefer CF, Anthony K, Krupa S, Buchoff J, Day M, Hannay T, et al. PID: the pathway interaction database. Nucleic Acids Res. 2009;37:D674-9.

38. Subramanian A, Tamayo P, Mootha VK, Mukherjee S, Ebert BL, Gillette MA, et al. Gene set enrichment analysis: a knowledge-based approach for interpreting genome-wide expression profiles. Proc Natl Acad Sci U S A. 2005;102:15545-50.

39. Tarca AL, Draghici S, Khatri P, Hassan SS, Mittal P, Kim JS, et al. A novel signaling pathway impact analysis. Bioinformatics. 2009;25:75-82.

40. Szklarczyk D, Franceschini A, Wyder S, Forslund K, Heller D, Huerta-Cepas J, et al. STRING v10: protein-protein interaction networks, integrated over the tree of life. Nucleic Acids Res. 2015:43:D447-52.

41. Kim KH, Dobi A, Shaheduzzaman S, Gao CL, Masuda K, Li H, et al. Characterization of the androgen receptor in a benign prostate tissuederived human prostate epithelial cell line: RC-165N/human telomerase reverse transcriptase. Prostate Cancer Prostatic Dis. 2007;10:30-8.

42. Yamada S, Pokutta S, Drees F, Weis WI, Nelson WJ. Deconstructing the Cadherin-catenin-Actin complex. Cell. 2005;123:889-901.

43. Otey CA, Carpen O. Alpha-actinin revisited: a fresh look at an old player. Cell Motil Cytoskeleton. 2004:58:104-11.

44. Hynes RO. Integrins: bidirectional, allosteric signaling machines. Cell. 2002; 110:673-87.

45. Sternberg PW, Schmid SL. Caveolin, cholesterol and Ras signalling. Nat Cell Biol. 1999;1:E35-7.

46. Hill MM, Bastiani M, Luetterforst R, Kirkham M, Kirkham A, Nixon SJ, et al. PTRF-Cavin, a conserved cytoplasmic protein required for caveola formation and function. Cell. 2008;132:113-24.

47. Garg M, Braunstein G, Koeffler HP. LAMC2 as a therapeutic target for cancers. Expert Opin Ther Targets. 2014;18:979-82.

48. Ponta H, Sherman L, Herrlich PA. CD44: from adhesion molecules to signalling regulators. Nat Rev Mol Cell Biol. 2003;4:33-45.
49. Sironen RK, Tammi M, Tammi R, Auvinen PK, Anttila M, Kosma VM. Hyaluronan in human malignancies. Exp Cell Res. 2011;317:383-91.

50. Popowicz GM, Schleicher M, Noegel AA, Holak TA. Filamins: promiscuous organizers of the cytoskeleton. Trends Biochem Sci. 2006;31:411-9.

51. Savoy RM, Ghosh PM. The dual role of filamin a in cancer: can't live with (too much of) it, can't live without it. Endocr Relat Cancer. 2013;20:R341-56.

52. Timofeeva OA, Zhang X, Ressom HW, Varghese RS, Kallakury BV, Wang K, et al. Enhanced expression of SOS1 is detected in prostate cancer epithelial cells from African-American men. Int J Oncol. 2009;35:751-60.

53. Yang G, Addai J, Ittmann M, Wheeler TM, Thompson TC. Elevated caveolin-1 levels in African-American versus white-American prostate cancer. Clin Cancer Res. 2000;6:3430-3.

54. Woodson K, Hayes R, Wideroff L, Villaruz L, Tangrea J. Hypermethylation of GSTP1, CD44, and E-cadherin genes in prostate cancer among US blacks and whites. Prostate. 2003;55:199-205.

55. Cavallaro U, Christofori G. Cell adhesion and signalling by cadherins and Ig-CAMs in cancer. Nat Rev Cancer. 2004;4:118-32.

56. Cavallaro U, Christofori G. Multitasking in tumor progression: signaling functions of cell adhesion molecules. Ann N Y Acad Sci. 2004;1014:58-66.

57. lozzo RV, Sanderson RD. Proteoglycans in cancer biology, tumour microenvironment and angiogenesis. J Cell Mol Med. 2011;15:1013-31.

\section{Submit your next manuscript to BioMed Central and we will help you at every step:}

- We accept pre-submission inquiries

- Our selector tool helps you to find the most relevant journal

- We provide round the clock customer support

- Convenient online submission

- Thorough peer review

- Inclusion in PubMed and all major indexing services

- Maximum visibility for your research

Submit your manuscript at www.biomedcentral.com/submit
Biomed Central 